\title{
Nondestructive Technique Survey for Assessing Integrity of Composite Firing Vessel
}

A. Tran

August 1, 2000

U.S. Department of Energy

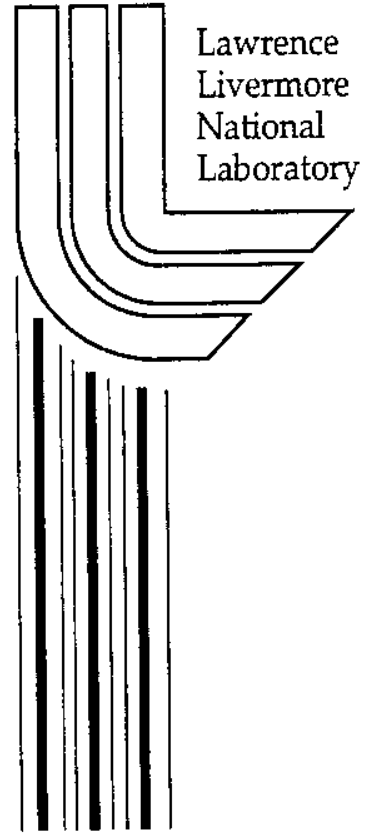




\section{DISCLAIMER}

This document was prepared as an account of work sponsored by an agency of the United States Government. Neither the United States Government nor the University of California nor any of their employees, makes any warranty, express or implied, or assumes any legal liability or responsibility for the accuracy, completeness, or usefulness of any information, apparatus, product, or process disclosed, or represents that its use would not infringe privately owned rights. Reference herein to any specific commercial product, process, or service by trade name, trademark, manufacturer, or otherwise, does not necessarily constitute or imply its endorsement, recommendation, or favoring by the United States Government or the University of California. The views and opinions of authors expressed herein do not necessarily state or reflect those of the United States Government or the University of California, and shall not be used for advertising or product endorsement purposes.

Work performed under the auspices of the U. S. Department of Energy by the University of California Lawrence Livermore National Laboratory under Contract W-7405-Eng-48.

This report has been reproduced directly from the best available copy.

Available to DOE and DOE contractors from the

Office of Scientific and Technical Information

P.O. Box 62, Oak Ridge, TN 37831

Prices available from (423) 576-8401

http://apollo.osti.gov/bridge/

Available to the public from the National Technical Information Service

U.S. Department of Commerce 5285 Port Royal Rd., Springfield, VA 22161 http://www.ntis.gov/

OR

Lawrence Livermore National Laboratory

Technical Information Department's Digital Library http://www.llnl.gov/tid/Library.html 
BEST AVAILABLE COPY

FOR ORIGINAL REPORT

CALL

REPORTS LIBRARY

X37097 



\title{
Nondestructive Technique Survey for Assessing Integrity of Composite Firing Vessel
}

\author{
A. Tran \\ Electrical Engineering Department, University of the Pacific
}

August 2000

Lawrence Livermore National Laboratory

University of California, Livermore, CA 94550 


\section{TABLE OF CONTENTS}

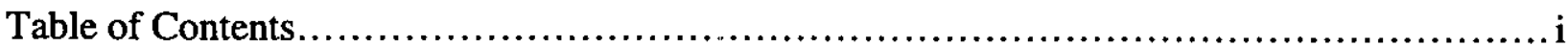

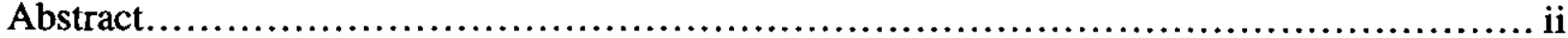

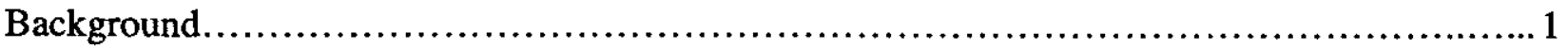

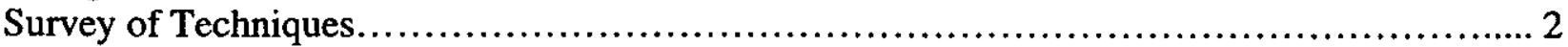

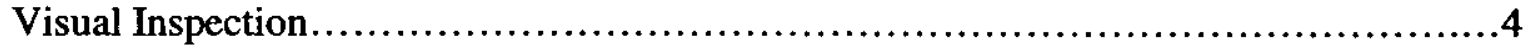

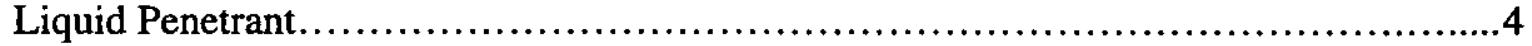

Magnetic Particle................................................................. 5

Surface Mounted Strain Gauges..................................................... 6

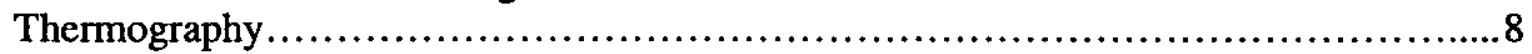

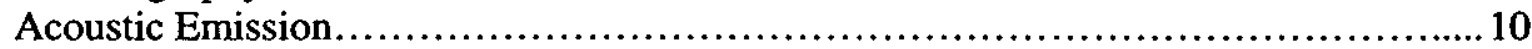

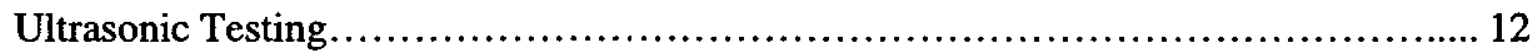

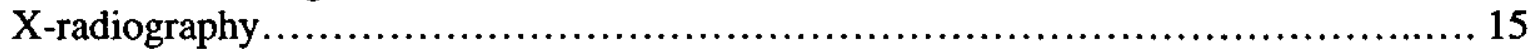

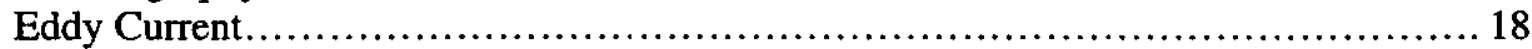

Embedded Fiber Optic Sensors................................................ 19

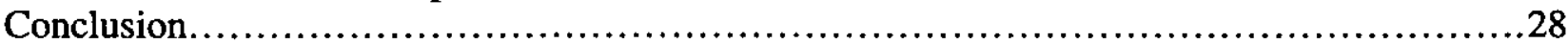

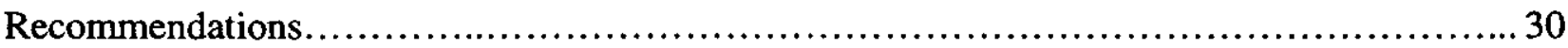

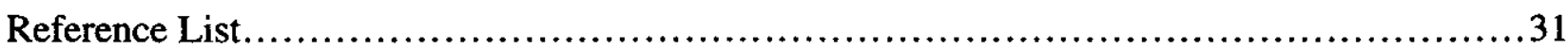

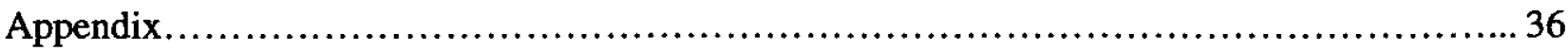




\begin{abstract}
The repeated use and limited lifetime of a composite firing vessel compel a need to survey techniques for monitoring the structural integrity of the vessel in order to determine when it should be retired. Various nondestructive techniques were researched and evaluated based on their applicability to the vessel. The methods were visual inspection, liquid penetrant testing, magnetic particle testing, surface mounted strain gauges, thermal inspection, acoustic emission, ultrasonic testing, radiography, eddy current testing, and embedded fiber optic sensors. It was determined that embedded fiber optic sensor is the most promising technique due to their ability to be embedded within layers of composites and their immunity to electromagnetic interference.
\end{abstract}




\section{Nondestructive Technique Survey for Assessing Integrity of Composite Firing Vessel}

\section{BACKGROUND}

Contained firing vessels protect radiographic lines of sight and diagnostic instrumentation from blast and shrapnel during explosive testing. They also protect the environment from potential toxic debris contamination. These vessels are typically made of steel with defined numbers of lines of sight. However, a composite vessel offers several additional advantages. A composite vessel possesses greater strength to weight and stiffness to weight characteristics than a steel vessel, and its low density permits radiography through the vessel wall. This windowless feature allows unlimited number of radiographic lines of sight and reduces the chance of leakage through the vessel.

At Lawrence Livermore National Laboratory, a composite firing vessel is being designed to support several advanced radiography projects. This windowless, spherical vessel is two meters in diameter and wrapped with four inches thick of Kevlar 49 over an aluminum shell (Figure 1). Generally, the aluminum shell (Figure 2) is the sealing member that prevents leakage through the vessel, while the Kevlar acts as a load-bearing, structural member.
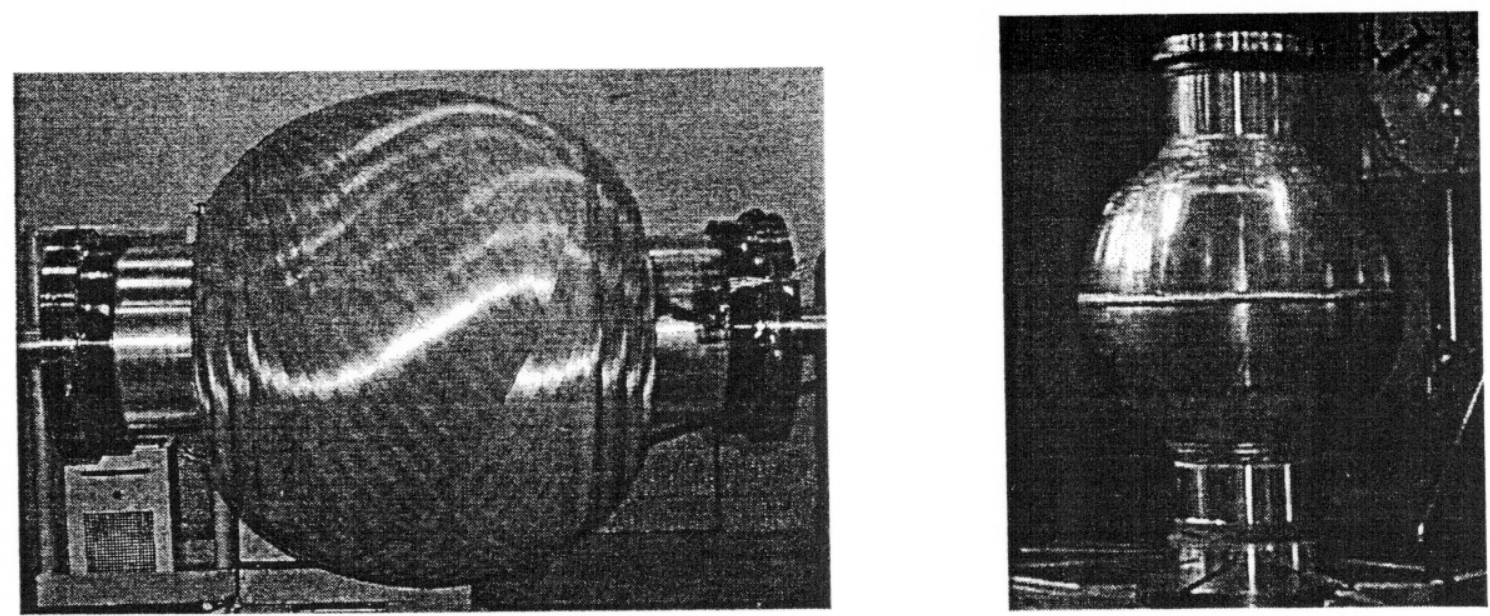

Figure 1. Half scale prototype of vessel with Kevlar overwrap

Figure 2. Aluminum shell of half scale prototype

Since the composite firing vessel could be used repeatedly, it is very important to monitor the structural integrity of the vessel in order to determine when it should be retired. The vessel can fail due to fatigue or fracture in the aluminum liner or several damage mechanisms in the 
accepted and understood. Composites, such as Kevlar, present more of a problem because of their numerous damage mechanisms and failure modes. When composites are loaded, three basic damages can occur - matrix cracking, delamination, and fiber breakage. Of the three mechanisms, fiber breakage is the most damaging. Damage growth in composites also differs from those in homogenous materials. When damage exists in a homogenous material, increasing the load will most likely cause the existing damage to increase. However, for composites, damage tends to relieve stress in the surrounding area, so that the next crack will usually appear somewhere else. This phenomenon makes it more difficult to predict damaged areas in composites. Larger cracks are produced when these microcracks accumulate in a common area [26]. Much research has been done on diagnostic methods for static loading of composites, but diagnostic methods for dynamic loading are less mature. Therefore, there is a need to survey applicable techniques for inspection of composites. Since the exact failure mechanism cannot be known without testing the vessel, this survey will help narrow down the number of options.

\section{SURVEY OF TECHNIQUES}

A survey of different nondestructive techniques is presented - visual inspection, liquid penetrant testing, magnetic particle testing, surface mounted strain gauges, thermal inspection, acoustic emission, ultrasonic testing, radiography, eddy current testing, and embedded fiber optic sensors. While this is far from a complete listing, it covers most of the primary nondestructive technologies available today. Visual inspection, liquid penetrant testing, and magnetic particle testing are primarily used to detect surface flaws. Techniques such as thermography and acoustic emission are considered global techniques because they enable large structures to be inspected very rapidly. However, localized techniques such as ultrasonic testing, radiography, and eddy current, offer higher resolution and are better for characterizing defects [16]. For more complex applications, multiple techniques are often used to effectively and efficiently monitor the structure.

A chart listing each technique and its primary advantages and limitations is presented in Table 1 followed by a detailed discussion of each technique. 


\begin{tabular}{|c|c|c|}
\hline METHOD & ADVANTAGES & LIMITATIONS \\
\hline Surface mounted strain gauges & $\begin{array}{l}\text { - } \text { apply to all materials } \\
\text { - real-time measurements }\end{array}$ & $\begin{array}{l}\text { only make surface } \\
\text { measurements } \\
\text { subject to electrical shot } \\
\text { noise }\end{array}$ \\
\hline Visual Inspection & - simplest method & - defects must be visible \\
\hline Liquid Penetrant & $\begin{array}{l}\text { - applies to almost any } \\
\text { shape/size } \\
\text { - } \text { simple process }\end{array}$ & $\begin{array}{l}\text { - defects must be opened to } \\
\text { surface }\end{array}$ \\
\hline Thermal Inspection & $\begin{array}{l}\text { - quick way to inspect large } \\
\text { structures }\end{array}$ & $\begin{array}{l}\text { sensitivity decreases with } \\
\text { depth of surface }\end{array}$ \\
\hline Ultrasonic Testing & $\begin{array}{l}\text { - can penetrate thick } \\
\text { materials } \\
\text { - can be automated }\end{array}$ & $\begin{array}{l}\text { - } \begin{array}{l}\text { require coupling } \\
\text { - limited by test object } \\
\text { geometry }\end{array} \\
\end{array}$ \\
\hline Acoustic Emission & $\begin{array}{l}\text { - can monitor entire system } \\
\text { at once } \\
\text { can provide information on } \\
\text { possible locations of defects }\end{array}$ & $\begin{array}{l}\text { - cannot determine size of } \\
\text { defects } \\
\text { - system can be too sensitive }\end{array}$ \\
\hline Radiography & $\begin{array}{l}\text { - can inspect wide range of } \\
\text { material/thicknesses }\end{array}$ & $\begin{array}{l}\text { - cracks must be parallel to } \mathrm{x} \text { - } \\
\text { ray beam } \\
\text { - expensive equipment }\end{array}$ \\
\hline Embedded fiber optic sensors & $\begin{array}{l}\text { real-time measurements } \\
\text { insensitive to } \\
\text { electromagnetic } \\
\text { interference } \\
\text { can be embedded into } \\
\text { structure throughout the } \\
\text { thickness; compatible with } \\
\text { composites } \\
\end{array}$ & $\begin{array}{l}\text { caution with imbedding } \\
\text { process } \\
\text { - can't be repaired } \\
\text { - immature/developing } \\
\text { technique }\end{array}$ \\
\hline Eddy Current & $\begin{array}{l}\text { - sensitive to small } \\
\text { discontinuities } \\
\text { - can be automated } \\
\end{array}$ & $\begin{array}{l}\text { - limited to electrically } \\
\text { conductive material } \\
\text { - low penetration } \\
\end{array}$ \\
\hline Magnetic Particle Testing & $\begin{array}{l}\text { sensitive to both surface } \\
\text { and near surface flaws }\end{array}$ & $\begin{array}{ll}- & \text { apply only to ferromagnetic } \\
\text { materials }\end{array}$ \\
\hline
\end{tabular}

Table 1. Primary advantages and limitations of nondestructive techniques. Eddy current and magnetic particle testing are not applicable for most composites. 


\section{Visual Inspection}

Visual inspection is the easiest method to implement. It can be done with the unaided human eye or with the aide of magnification loupes or dye penetrants. Both the outer surface and the inside of the liner can be visually inspected for defects [18]. The primary drawback to visual inspection is that only visible flaws can be detected. Even detection of surface defects can be limited by one's visual access to the test object [3]. There may not be any obvious visual signs if the composite has been weakened due to broken fibers or delamination [18]. Therefore, visual inspection alone is inadequate for assessing the integrity of the vessel.

\section{Liquid Penetrant $[1,3,4,6,7,12]$}

Liquid penetrant testing is an offshoot of visual inspection. It can be used to inspect all nonporous, nonabsorbing materials. This technique is generally developed for homogenous materials, such as metals, but it can also be applied to composites. A penetrant, usually liquid but may be gaseous, is applied to the surface of the test object and drawn into the cracks by capillary action. There are two classes of penetrant visible, which can be examined in ordinary white light, and fluorescent, which requires the excitation by ultraviolet radiation. Fluorescent penetrant is better for detecting small discontinuities. Selection of penetrant type should be based on several criteria - type of surface being inspected, processing to be used, sensitivity desired, and roughness or porosity of the surface. There is also the possibility of the solvent reacting with the composite material. The developer, which can be a dry powder or an aqueous solution, then draws the penetrant out of the cracks and creates a contrasting background for inspection. Different types of lighting, such as white light or ultraviolet light, can be used to inspect the surface for defects. Defects are evident by the increase in brilliance of the fluorescent dye or by contrast to the background for the visible dye (Figure 3).

The advantages of liquid penetrant testing are similar to those of visual inspection. It is a simple technique that does not require expensive material or equipment. It can be applied to 
objects of almost any shape, size or geometry. Penetrant testing is also an extremely sensitive technique. It can detect microcracks as small as 1 micron in width [12].

Major limitations of liquid penetrant testing are that it can only detect flaws that are opened to the surface and not able to determine the depth of discontinuities. Access to the object is required for the application of penetrant and developer as well as surface cleaning. Many factors, such as surface cleanliness, temperature of the object, penetrant and object compatibility, and time the developer remains in the object, can affect the accuracy of the results. When inspecting the surface, one must be aware of false indications caused by incomplete removal of excess penetrant or surface contamination, and irrelevant indications caused by factors such as geometric sharpness of the object. Due to the multiple steps in the procedure, long processing time is required. It is also difficult to produce a permanent record with liquid penetrant testing.

There does not appear to be a need to apply liquid penetrant testing to the vessel. Surface cracks will develop in the epoxy material, but they are not necessarily indicative of the damage or integrity of the filament wound fiber. Sensitivity is not too important since small cracks are not damaging enough to cause the vessel to be retired. For large surface cracks, visual inspection might suffice.

Magnetic Particle Testing [3, 5, 6, 8, 12]

Magnetic particle testing utilizes the accumulation of magnetic powder to indicate flaws in a structure. The underlying concept of magnetic particle testing is that when a bar magnet is cracked or broken, each broken piece will act as a separate magnet, possessing its own distinctive north and south poles. This phenomenon creates a magnetic leakage field consisted of distorted magnetic lines of force to the cracks (Figure 4).

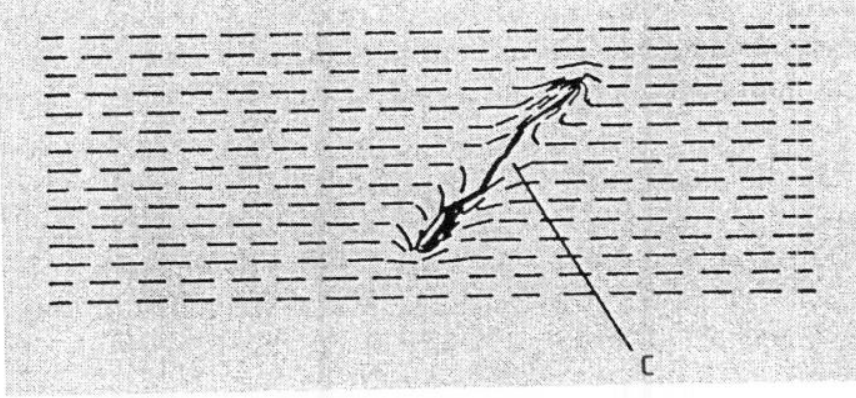

Figure 4. Magnetic leakage field around surface crack (C) [5]

Magnetic particle testing can only be applied to ferromagnetic materials. Even though it is mostly used for detecting discontinuities that are opened to the surface, it can also detect discontinuities that are slightly below the surface. Generally, the maximum depth below the surface at which flaws can still be detected is about $1.5 \mathrm{~mm} \mathrm{[5].} \mathrm{Shaped,} \mathrm{angular} \mathrm{discontinuities}$ are usually more easily located than round, streamlined ones. Magnetic particle testing can detect cracks up to $0.5 \mathrm{~mm}$ in length [6]. 
When performing magnetic particle testing, the surface must be prepared by removing all the grease and dust. The object is then magnetized by inducing a current through it. The defect is best revealed if it is oriented parallel to the current. Alternating current (AC) magnetization is most effective for surface defects, and direct current (DC) magnetization is required for subsurface defects. Magnetic particles are then applied over the surface of the object. The magnetic leakage fields are outlined when these particles are drawn to the cracks (Figure 5). Different lighting might be required for inspection of flaws on the surface of the object. The final step is demagnetizing the object.

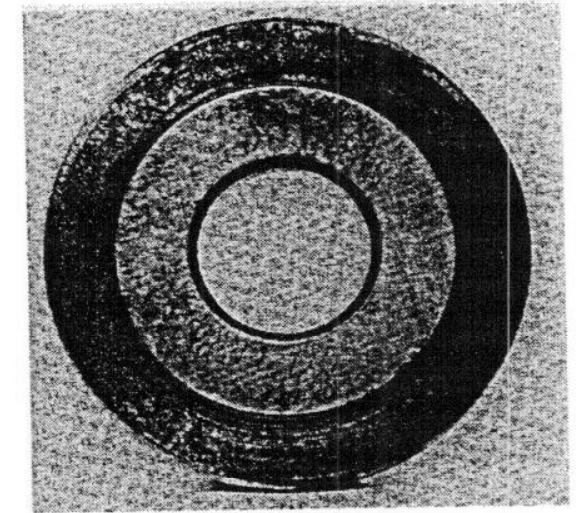

Figure 5. Magnetic particle indicates cracks on steel bearing [5]

There are two classes of magnetic particles - wet and dry. Wet particles are best for detecting fine surface cracks, such as fatigue cracks. Their mobility enables them to cover large, irregularly shaped objects fairly easily and quickly. Concentration can easily be controlled, and these particles can be recovered and reused. They can also be used for automated testing. The disadvantages of wet particles are that they are messy and cannot detect cracks that are located beneath the surface. On the other hand, dry particles are excellent for locating defects beneath the surface. This method is much cleaner than the wet method and can be easily used with portable equipment. However, they are not as sensitive to small defects. It is also difficult for them to completely cover entire surfaces, especially for large and irregularly shaped objects. The process is much slower, and it is difficult to incorporate them into automated systems.

Magnetic particle testing is a cost-effective method for detecting near surface and surface flaws. However, it requires a clean and relatively smooth surface. There may be some difficulties in demagnetizing the object afterwards. The biggest limitation to this method is that it can only be applied to ferromagnetic materials, which Kevlar and aluminum are not. Therefore, magnetic particle testing is not a suitable technique for inspecting the shell composite firing vessel, but may be applicable to the ferros end plugs and the clamps of the vessel.

\section{Surface mounted strain gauges $[2,12,20]$}

Bonded resistance strain gauges measure the deformation of an object based on the changes in the electrical resistances of the conductor attached to it. The basic configuration of a strain gauge is shown in Figure 6. When an object is deformed, the strain in the object is transmitted to the grid through the adhesive. This modifies the cross sectional area of the wire, which changes its resistance. The resistance is then measured by a Wheatstone bridge circuit (Figure 7). 


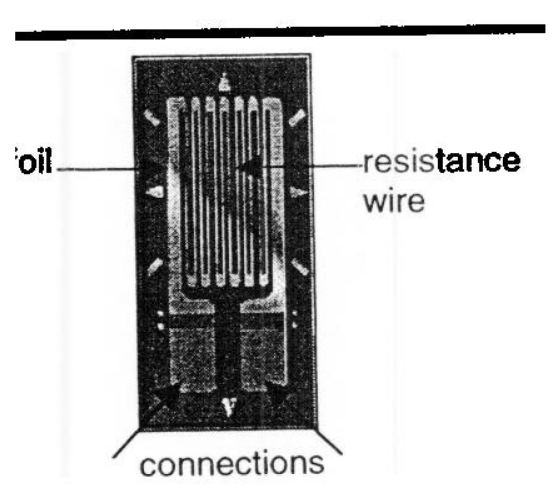

Figure 6. Basic strain gauge configuration

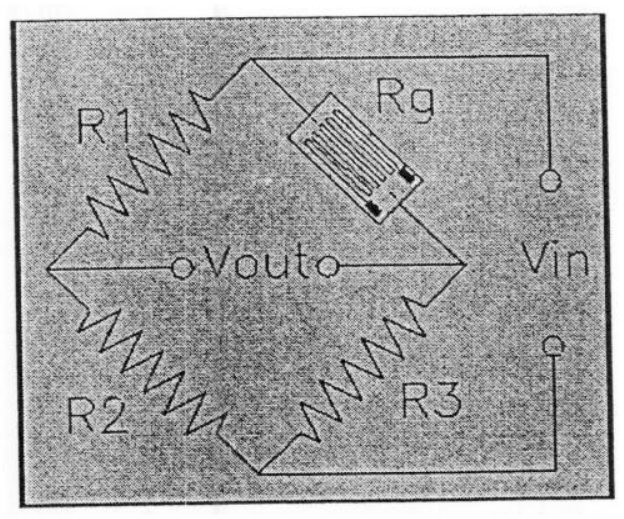

Figure 7. Wheatstone Bridge Circuit [21]

When there is no resistance in the wire, a zero output voltage indicates a balanced bridge circuit. However, when the resistance of the wire changes, the bridge becomes unbalanced, and an output voltage results. This output voltage is then converted to strain measurements using the equation:

$$
\text { Strain }=\left(\Delta \mathrm{R}_{\mathrm{g}} / \mathrm{R}_{\mathrm{g}}\right) / \mathrm{GF}
$$

$$
\text { where } \begin{aligned}
\mathrm{R}_{\mathrm{g}}=\text { strain gauge resistance } \\
\mathrm{GF}=\text { gauge factor (also strain sensitivity) }
\end{aligned}
$$

For the testing of the half scale prototype of the composite firing vessel, surface mounted strain gauges are used to monitor the vessel. Strain gauges, pressure transducers, and temperature sensors are mounted on the surface of the aluminum liner (Figure 8) and the Kevlar overwrap (Figure 1). The instrumentation measures the blast effects and overall structural response of the vessel. These strain gauges are placed in locations of highest anticipated strains determined by computer modeling of the vessel response.

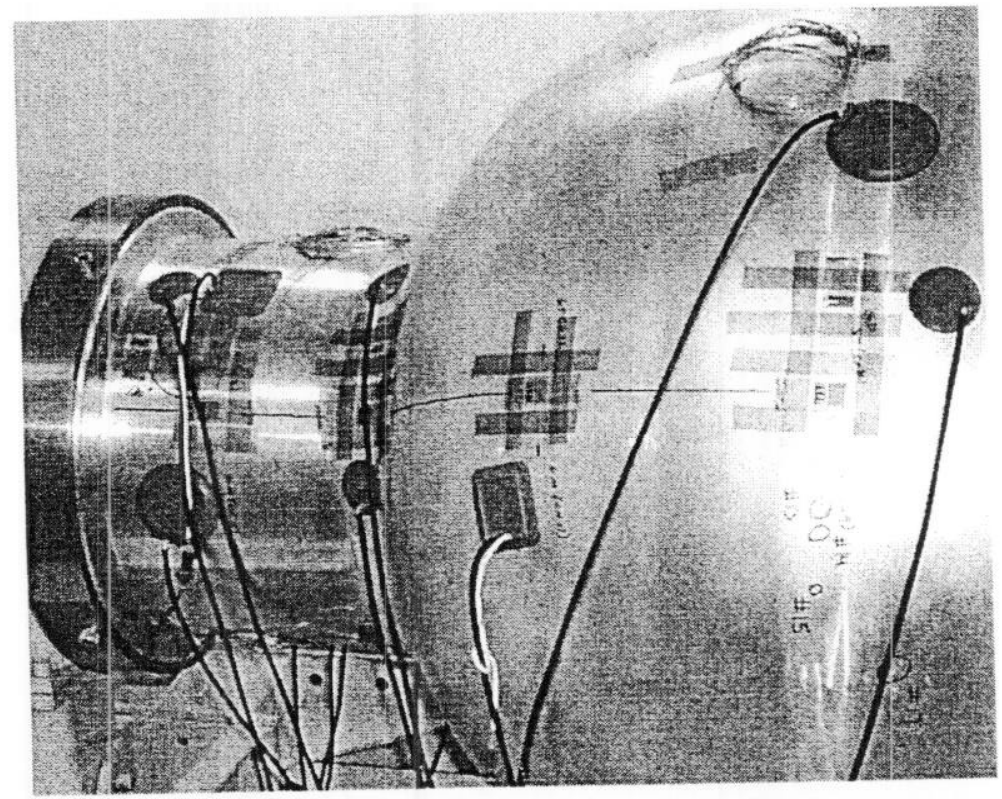

Figure 8. Bonded resistance strain gauges and temperature sensors installed on aluminum liner of half scale prototype 
One of the advantages of surface mounted strain gauges is their ability to perform measurements on all types of materials. They are lightweight, small in size, although gauge lengths from $0.008 \mathrm{in}$. to $4 \mathrm{in}$. are available, and come in different shapes and sizes [20]. They generally achieve accuracy within $+/-0.10 \%$ and can measure strain to 1 micron per meter $[12$, $20]$. For the prototype vessel, the strain limit for the gauges on the liner is approximately $+/-20 \%$ and $+1-3 \%$ for the gauges on the composite. Strain gauges offer simple data interpretation as well as real-time measurements. Both static and dynamic strain can be measured with these gauges. An added benefit is that this technique is a reliable and well-understood method that has been around for a long time.

Despite their advantages, surface mounted strain gauges are inadequate for assessing the integrity of the vessel. The major disadvantage is that they can only measure surface strain. Since the strain gauge is directly applied over the resin, the gauge only measures the strain experienced by the resin. Ideally, the resin should experience the same strain as the fiber, but that is not always the case. Degradation of the bond, temperature influences, and matrix cracks, can lead to erroneous measurements [20]. Another problem is that since the fiber layers are 4 inches thick, the fiber on the surface may experience different strain from the fiber on the bottom layers. Sub-surface fibers cannot be monitored with surface-mounted strain gauges. Another limitation is its inability to detect fiber breakage or delamination unless the gauge rests directly above the defect location. Computer models are currently used to predict the areas of highest anticipated strain. However, there is no way of detecting damage in areas that strain gauges are not installed on, which can be devastating if these models are incorrect. Bonded resistance strain gauges are also subject to electrical shot noise. Finally, these gauges are permanently bonded to the test object, which makes the ones that are bonded on the aluminum liner irreplaceable if they are destroyed.

Thermography $[1,3,4,9,11,12,16]$

Thermal inspection uses heat-sensing devices to measure the temperature or thermal gradient of an object when it is heated or cooled. Research is currently being done using this relatively new method to monitor the structural integrity of aerospace and marine structures [22, 23]. Thermal inspection operates on the principle that defects vary the thermal profile of structures. When an entire surface is heated, the temperature above a defect will rise more rapidly because there is less mass to store the heat. On the other hand, when an entire surface is cooled, the area over the defect will cool faster. A region with a defect has a lower thermal impedance than an undamaged area, while a disbonded region has a higher thermal impedance than an undamaged area. Therefore, it is possible to locate areas of defects and disbands by observing the thermal image of a structure.

Thermography, a type of thermal inspection, is the mapping of contours of equal temperature over a surface. First of all, heat is uniformly applied to an object using external or internal means. External application of heat includes radiation, using heat lamps or lasers, 
convection, using blowers or ovens, and convection, using contact hot plates. Internal methods consist of converting electrical, magnetic, mechanical, or chemical energy into heat. Next, an infrared camera is used to map locations of hot spots. The sensitivity of infrared cameras is typically from 0.1 to $0.5^{\circ} \mathrm{C}$, and the temperature range is -20 to $1500^{\circ} \mathrm{C}$ [19]. Defects on the object are identified by comparing the gradient to pre-established standards.

Thermography is most effective in inspecting thin, isotropic materials with high thermal conductivity through the thickness of the material and low conductivity in the plane directions. Graphite/epoxy is highly anisotropic; in which case, the thermal image may become unrecognizable given a sufficient number of plies [11]. For the same reason, Kevlar is also poorly adapted for thermal imaging [16].

Thermography was used to inspect a $12 \times 12$ inch, 192 ply thick, graphite fiber panel that was subject to fatigue loading until failure. Damage in the outer 0-20 plies of the panel were indicated during the $32 \%$ mark of the fatigue life. The temperature rise in this area was about $5^{\circ} \mathrm{C}$. After the panel has reached catastrophic failure, the temperature rise in the damaged areas increased to $40^{\circ} \mathrm{C}$ [17]. A 70-inch long, 42-inch diameter, graphite/epoxy filament wound tank was tested to failure. Thermography was successful in locating all the areas of delaminations that were detected by ultrasonic testing. Even when applied manually, it took as little as ten minutes to inspect the entire tank using thermography [11].

A major advantage of thermography is its ability to rapidly inspect entire structures. The acquisition of thermal images is very quick, which dramatically reduces the inspection time. This is especially beneficial when inspecting large structures such as the composite firing vessel. This non-contacting technique also enables data to be acquired remotely. It can detect disbonds in adhesive joints and delaminations in composites.

Disadvantages to thermography include its limited sensitivity for deep delaminations. In fact, sensitivity decreases with depth of surface, causing it to be ineffective with thick materials. Johnson [18] reported that thermographic images of an aluminum sphere wrapped with graphite fiber (26.6 in diameter) clearly indicated locations of defects when 45 Joules (J) of impact energy was applied to it (Figure 9). However, the technique failed to detect damage to vessels with thicker overwraps and/or liners $(>4.6 \mathrm{~mm}$ ) even when the impact energy was increased to $50 \mathrm{~J}$ [18]. Another limitation to thermography is its inability to determine depth of defects. Thermography merely gives a qualitative indication of the overall structural integrity of an object. The variable surface emissivity of different objects also makes it difficult to interpret results. When inspecting materials with low emissivity such as metals, a special coating may be required to ensure that enough energy is transferred to the surface of the object. Defects on the surface may produce a higher thermal gradient than a crack within the object. In this respect, the data can be somewhat misleading because a crack within the object might have a larger impact on the object than a surface defect. Thermography works best with flat, planer components as opposed to curved, spherical objects. The equipment and instrumentation used in thermography are also relatively expensive compared to those used for other methods. 

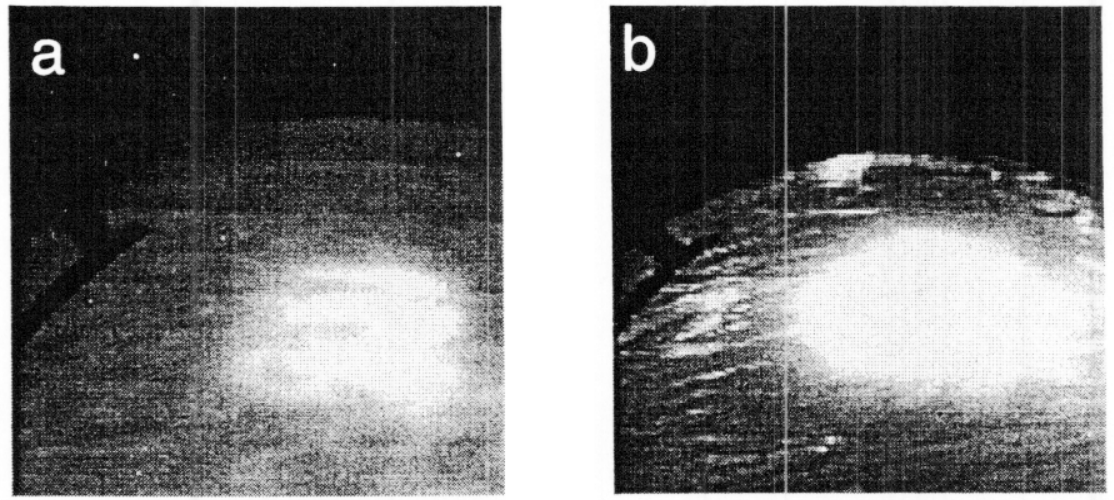

Figure 9.

a) Thermographic image of vessel taken $1 \mathrm{sec}$ after heating with flash lamp [18]

b) Thermographic image of vessel taken $\sim 5 \mathrm{sec}$ after heating with quartz lamp [18]

The quick processing time of thermography makes it an attractive technique for monitoring the composite firing vessel. However, this method alone is inadequate for assessing the integrity of the vessel. It may be possible to use thermography to scan the entire vessel for possible defect locations and then applying ultrasonics or radiography to characterize the defect and obtain quantitative data. Since this is a relatively new technique, much work still needs to be done in improving its reliability. Its ineffectiveness in examining thick materials, however, raises a concern since the four inch thick overwrap on the vessel is substantially thicker than the composites on aerospace structures, whose defects were successfully detected using thermography [22].

Acoustic Emission $[3,4,9,12,13,16]$

Deformation in a material causes rapid releases of energy, generating elastic stress waves. These acoustic emission (AE) waves then strike the object surface and cause the surface molecules to move. Acoustic emission sensors detect the movements and convert them to electrical signals. Acoustic emission sources or events include matrix cracking and fiber debonding at low strain level in composites, fiber fracture at medium strain level, delamination at high strain level, and fiber pullout. Acoustic emission occurs at yield stress of a material and is often used to detect the onset of damage by observing the time when the first AE occurs or the severity of damage by counting the number of acoustic emissions over a certain period of time. AE pulses are damped sinusoids with fast rise time; their duration range from nanoseconds to milliseconds.

Acoustic emission is a rather unique method because it differs from other nondestructive techniques in many ways. First of all, for acoustic emission, the energy detected is released from within the test object as opposed to being supplied by the nondestructive method. For example, thermography requires a heat source and ultrasonic testing requires a mechanism to generate sound waves, but in acoustic emission, the defect itself acts as the source of energy. Secondly, acoustic emission only detects dynamic processes such as crack growth. This is attributed to the Kaiser effect, which states that once a load has been applied to an object, additional acoustic emission will not occur until that stress level has been exceeded even if the load has been completely removed and then reapplied. Finally, unlike other techniques, acoustic emission 
does not require prior knowledge of probable location and orientation of the discontinuity. A sensor is often able to detect the resulting AE when it is located anywhere in the vicinity of the source. Most AE sources function as point source emitters that radiate energy in spherical wavefronts. Multiple sensors can triangulate or locate probable defect locations. Since crack size cannot be determined with acoustic emission, this method is generally used to complement other techniques, such as radiography or ultrasonics. AE, as a global technique, can be effective in narrowing down regions of inspections for other techniques.

There are two different types of AE signals - burst type (Figure 10) and continuous emission (Figures 11). Burst type signals, most common for fiber composites, are much higher in amplitude and energy. The individual stress wave bursts are seen, and each signal corresponds to an individual emission event. In general, low peak amplitude levels $(<50 \mathrm{~dB})$ correspond to matrix cracking, high peak amplitude levels $(>70 \mathrm{~dB})$ are produced from fiber breakage, and long duration levels $(>3 \mathrm{~ms}$ ) indicate delamination. On the other hand, continuous emission signals are much lower in energy. Rapidly occurring emission events generate a sustained signal level, and as the load increases, the amplitude of the emission also increases. Defects such as dislocation movements in metals generate continuous emission signals.

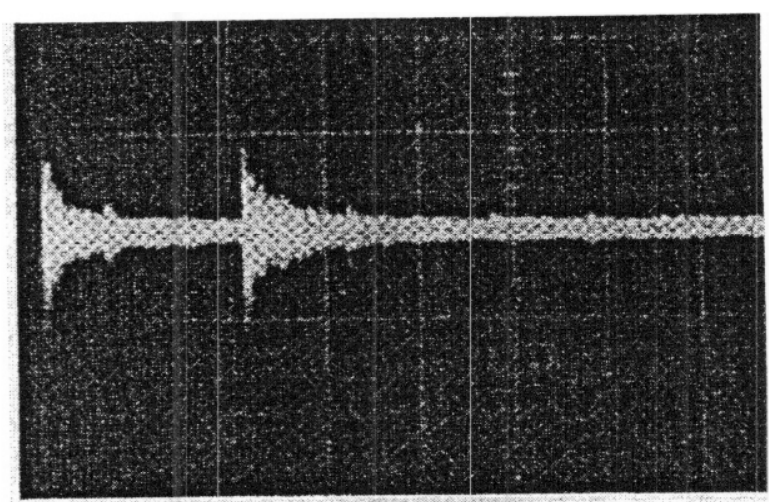

Figure 10. Burst type emission is characteristic of fibers [3]

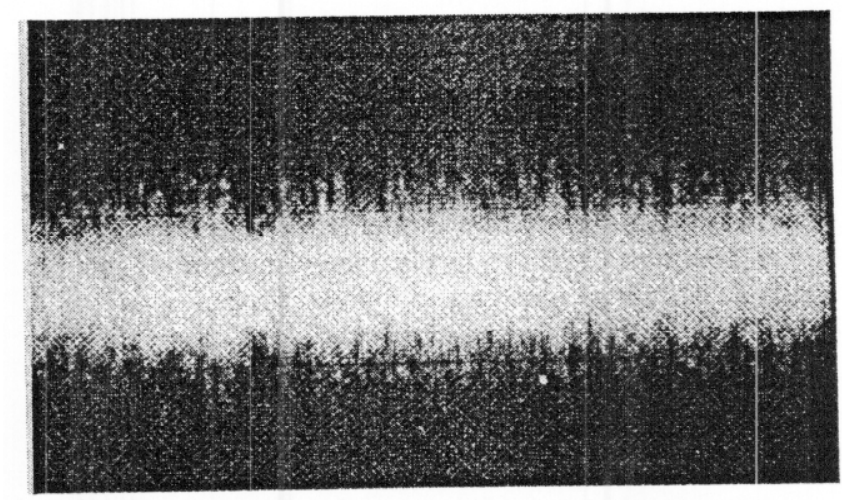

Figure 11. Continuous emission is characteristic of metals [3]

It was found that the type of loading also affected AE signals. In a study using acoustic emission to detect damage on a $12 \times 12$ inch, 192 ply thick, graphite fiber panel, the amplitude of the $\mathrm{AE}$ events during dynamic loading were $10-15 \mathrm{~dB}$ greater than those under static loading [17]. In general, acoustic emission signals produced from fiber-reinforced composites have much higher amplitudes than signals from metals. Close sensor spacing is required to compensate for the attenuation of AE signals in fiber-reinforced materials.

Gorman [17] noted that hydro-proofing filament wound pressure vessels before impacting them would eliminate most background emissions, making the detection of relevant AE events a lot easier. His experiments showed that there is a good correlation between the number of AE events and the burst pressure of the vessel [24]. Even though fiber breaks produce $\mathrm{AE}$, not all fiber breaks are detrimental to the vessel. The strength of the composite is not 
affected by widely separated fiber breaks. Delaminations can also have positive effects on a vessel. They can relieve stress in the vessel, which increases the burst-pressure strength of that vessel. Therefore, not all acoustic emission events would have a negative impact on the structure $[25]$.

Acoustic emission has numerous advantages. For most applications, it provides real-time records of damage. It allows for continuing and remote monitoring of the structure. Since it is a passive technique, no equipment is required to excite the pulse. Only limited access to the object is required. It is more sensitive than typical instruments to crack growth and able to determine the locations of crack growth. In fact, it is one of few nondestructive techniques that have the potential to detect all three damage mechanisms in composites - matrix cracking, delamination, and fiber breakage [26]. Perhaps the biggest advantage of acoustic emission is its ability to monitor an entire system at the same time. Since AE sensors are sensitive to energy releases in an entire structure, monitoring an entire structure can be done with a relatively small number of sensors.

Disadvantages of acoustic emission include its inability to determine the size of cracks and defects. In fact, due to the Kaiser effect, it cannot detect cracks that are not growing. This method is also limited to only being able to monitor materials that can emit enough sound during cracking or deformation. The biggest disadvantage of acoustic emission may be that the results produced are sometimes misleading and difficult to interpret. Sensitivity of the AE system causes it to pick up a lot of background noise, which may produce signals that are very similar to those from cracking, making it extremely difficult to decipher genuine emission from noise. A single acoustic emission source may be detected by multiple sensors, which makes locating the position of the defect a very difficult task. However, different techniques have been studied to solve this problem. Each sensor can be acoustically isolated so that it only detects sound from a given region [24]. A first hit analysis was also developed to identify the sensor that is nearest to the $\mathrm{AE}$ source. When a signal is detected by a sensor, all subsequent hits of that signal is ignored for a set period [26].

The advantage of being able to monitor the entire structure at once seems very attractive for the composite firing vessel. One can conceivably use acoustic emission to determine possible defect locations. However, the reliability of the results is questionable due to the extreme sensitivity of the system. Another limitation of this technique is that it cannot be used during the detonation of the vessel. Instead the fibers must be loaded by statically pressurizing the vessel. Therefore, real-time results cannot be provided using acoustic emission.

Ultrasonic Testing $[1,3,4,6,8,9,12,14,16]$

Ultrasonic testing uses the transmitting and receiving of high frequency vibrational waves to detect size and location of flaws. Electronically controlled pulses are introduced into the material from an outside surface. When an ultrasonic wave encounters a defect, the defect either decreases the speed of the wave by reducing the stiffness of the material or increases the attenuation in the wave. The energy is then received by a transducer and used for diagnostics. 
Ultrasonic testing detects flaws in metallic, non-metallic, and composite materials. Even though both internal and surface flaws can be detected, it is primarily used to detect flaws at great penetration depths. The sensitivity of ultrasonics does not vary too much with the thickness of the material, whereas the sensitivity of other techniques generally decreases substantially with the thickness. Ultrasonic testing best detects flaws that are perpendicular to the ultrasonic beam.

Most ultrasonic applications consist of four basic components - generator, transducer, couplant, and display device. A generator produces a high voltage pulse. A transducer converts the electrical energy to ultrasonic waves and vice versa. A couplant, can be a type of liquid or grease, prevents the sound waves from reflecting off the surface. Finally, a display device displays the signal for data interpretation and analysis. An oscilloscope generally displays an Ascan signal, which is pulse or amplitude versus time. This indicates the discontinuity depth and signal amplitude. B-scan uses recording paper or computer monitor to display size and position against the probe movement on a surface. This indicates the discontinuity depth and distribution in cross sectional view. C-scan also uses recording paper or computer monitor to display the size and position on an area parallel to the surface, which indicates the discontinuity position in plan view (Figure 12).

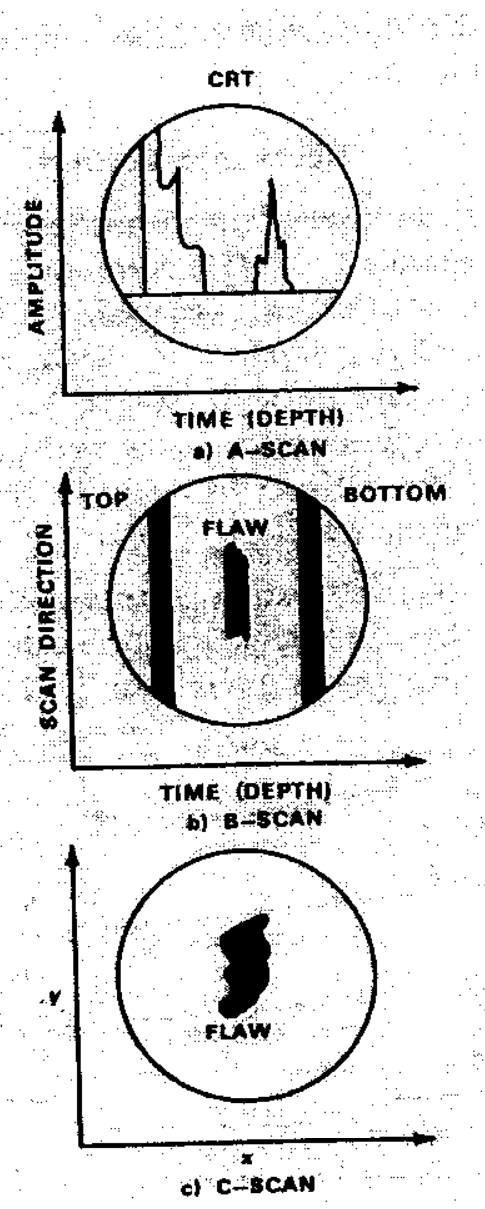

Figure 12. Ultrasonic display [8]

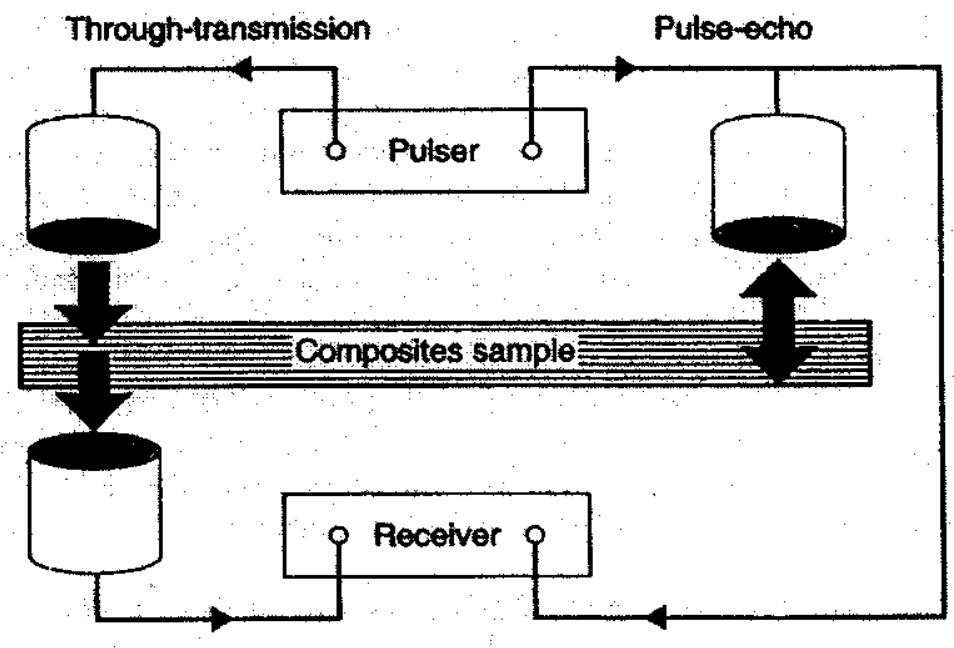

Figure 13. Schematic of through transmission and pulseecho methods [16] 
There are different types of ultrasonic testing, two of which are the through-transmission method and the pulse echo method (Figure 13). The through-transmission method utilizes a transducer to emit high frequency sound into the object. If a discontinuity is encountered, a small portion of the signal is scattered by the discontinuity. The remaining signal is received by another transducer located on the other side of the object. A greater discontinuity size results in a greater decrease in the intensity of the signal received. This method requires two transducers, one on each side of the object. It can detect flaws up to $0.2 \mathrm{~mm}$ in size [12]. Advantages to the through-transmission method are the abilities to test highly attenuating materials and near surface flaws. A major disadvantage is that both sides of the test object must be accessible to the operator, which may cause some difficulties in aligning the transducers.

The pulse-echo method utilizes a transducer to emit short, rapid pulses of high frequency sound from an outside surface. Flaws in the material will reflect the energy back to the receiver. A greater discontinuity size results in a greater signal received. This method typically uses the same transducer to emit and receive the signal. It can detect flaws up to $0.01 \mathrm{~mm}$ in size [12]. The primary advantage to the pulse-echo method is that it requires access to only one side of the object. This method is also able to distinguish flaws at different depths of the object (Figure 14). A disadvantage is that it is ineffective in inspecting highly attenuating materials. Since the distance that the signal has to travel is twice as long compared to the through transmission method, a significant loss in signal strength results. It is also difficult to inspect small or thin parts and near-surface flaws with the pulse-echo method.

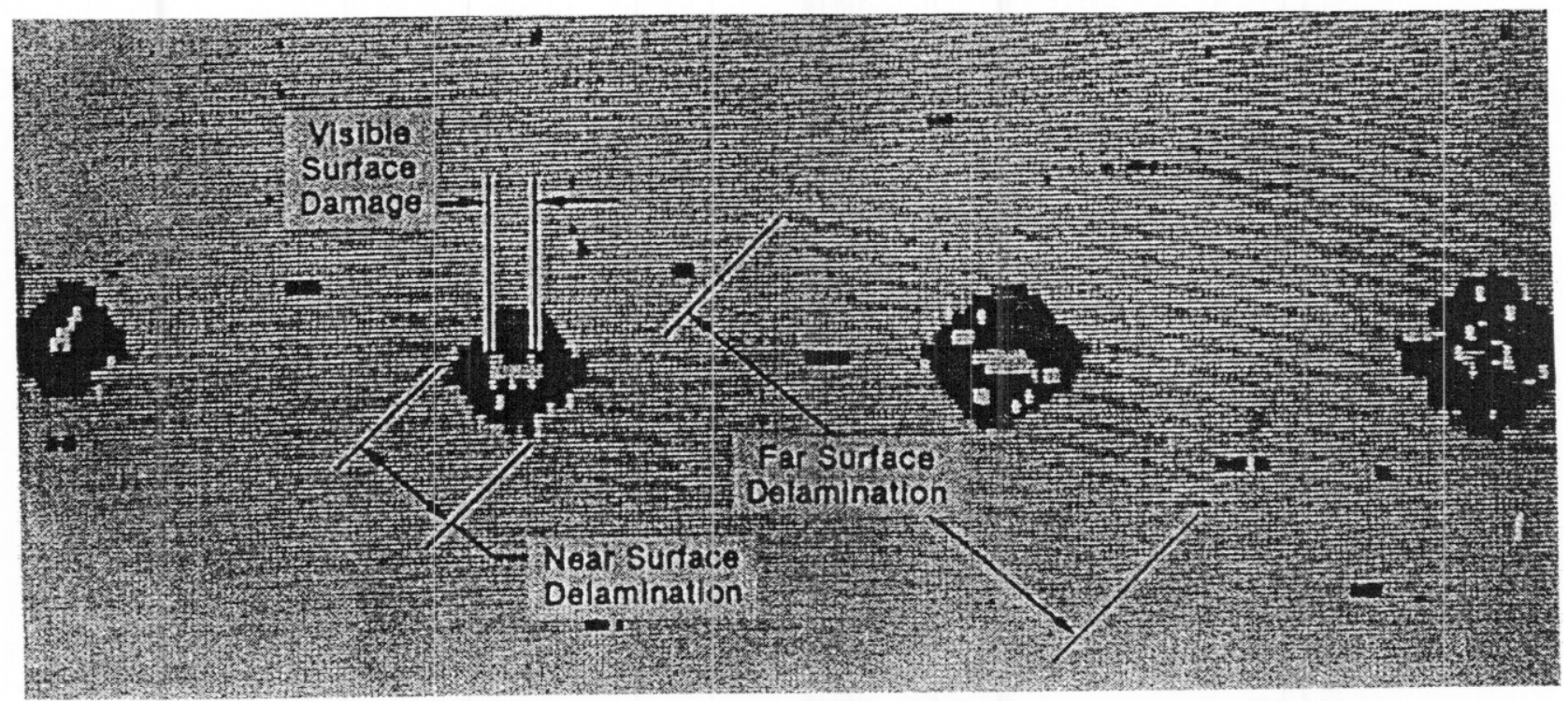

Figure 14. Pulse-echo ultrasonic C-scan showing flaws at different depths caused by impact damage [9]

Ultrasonic testing can also be applied in a couple ways - by contact or immersion. In the contact technique, the transducer touches the test object surface. This has the advantage of being able to adapt to large and irregularly shaped objects. However, it is difficult to attain uniform coupling with the contact technique. When applying the contact technique, another method is 
required to scan the entire object beforehand in order to locate the transducer position. The immersion technique involves placing the entire object and transducer into a water tank so that the water in the tank can act as a couplant between the object and the transducer. Advantages include good uniform coupling and ease in automating the tests. However, water corrodes most composite materials, including Kevlar. The hardware for this technique is also expensive and complex. Immersing the entire object in water is also impractical for big, heavy objects such as the composite firing vessel.

Kevlar has a very rough surface, causing ultrasonic energy to attenuate very rapidly. Therefore, to compensate for the high attenuation, low frequency transducers need to be used, which may cause a decrease in resolution. Glycerin is a better couplant for Kevlar than water is because water can damage the composite. Water also does not offer a good impedance match to the material. Due to the rough surface of the material, the contact technique works better than the immersion technique.

A flexible ultrasonic array system was developed by the U.S. army to inspect thick composite materials. The system features 1024 transducers arranged in a 32 by 32 matrix, spanning a total area of 64 square inches. The time required to electronically sequence through the arrays is less than one minute. In order to attain uniform coupling, the transducers are coupled to the structure using a vacuum system. This system offers many benefits over the traditional method of manually scanning the surface of an object with a single array - the most obvious one being inspection time [28].

Ultrasonic testing offers many advantages. It is very sensitive and has the ability to detect very minute discontinuities. Its good penetration power enables extremely thick sections to be examined. Ultrasonic testing provides accurate measurements of discontinuity position and size. Real-time results can be obtained, and the process can also be automated. Its use of low amplitude, inaudible sonic waves does not cause any damage to the test object. The method is also safe to use and does not cause major hazards to personnel.

Ultrasonic testing can be limited by the test object geometry, internal structure, and beam alignment. Sound waves tend to have difficulty reflecting directly back to the transducer when the object is irregularly shaped, while curved surfaces may focus or spread the beam. Large grain size, where the ultrasonic wavelength is approximately the size of the grain, can scatter the energy. Smaller grains, in which the wavelength is significantly larger than the grains, can reduce the sensitivity. In order for flaws to be detected, they must be oriented relatively perpendicular to the ultrasonic beam. Ultrasonic testing is also unable to detect fiber breakage. It has also been reported that in many cases, ultrasound $\mathrm{C}$-scan was unsuccessful in detecting damage in composite materials [49].

Compared to other nondestructive techniques, ultrasonic testing is among the top candidates for inspecting thick composites due to its sensitivity and penetration power. However, the weight and size of the firing vessel make it impractical to be immersed into a tank of water. In fact, water cannot even be used because it will corrode the Kevlar. There is the possibility of filling the inside of the vessel with water and putting the pulsar in the water. The sensors can be coupled onto the outside of the vessel using glycerin. However, a possible gap 
between the Kevlar overwrap and the aluminum liner may distort the signal received by the sensors. The contact technique is a possibility if the object can be scanned beforehand for regions where defects might possibly occur. Ultrasonics can then be used to verify the results and characterize the flaws. Another issue with the contact technique is the importance of attaining uniform coupling for such a large object. Therefore, some kind of automated system, such as the flexible ultrasonic array system described above, appears to be much more efficient and practical for our application.

$X$-Radiography $[1,3,4,6,8,9,12,16]$

Radiography produces a shadow picture of the internal structure of an object. First of all, $\mathrm{x}$-ray beams are directed toward an object to be examined. When the $\mathrm{x}$-rays hit the object, some parts of this beam are scattered, while others are absorbed. The amount of absorption is based on the thickness, physical density, and composition of the object as well as the type and size of the defects. The beam that is absorbed generates a shadow picture of the internal structure of the object. Radiography is applicable to metals, nonmetals, and composites and is best for finding internal, nonplanar defects.

$\quad$ Conventional
radiography utilizes
photographic film to record
the image produced. This
produces a sharp,
permanent image of the
flaws and enables results to
be easily interpreted.
However, this process is
extremely slow and can be
very expensive, depending
on the type of film used.
A newer type of
radiography is camera-
scintillator radiography.
This method utilizes
scintillators, which are
wide gap insulators, to

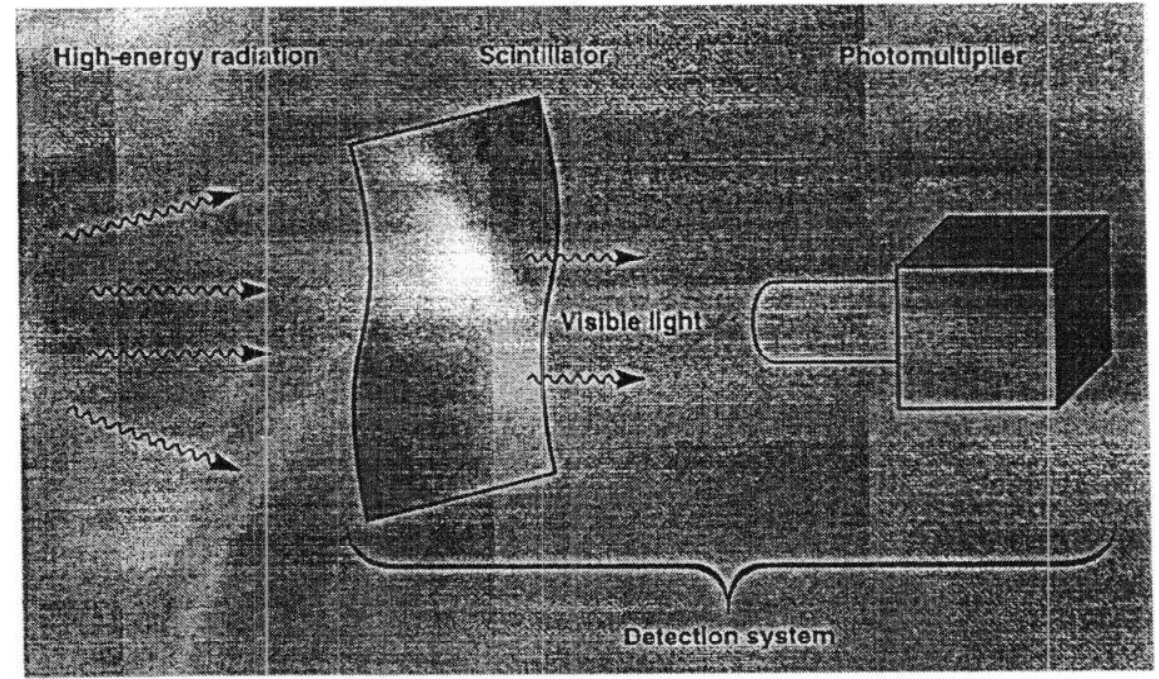

Figure 15. Scintillators convert $x$-rays into visible light. Photons can be detected and counted using a photomultiplier [32]. absorb the radiation energy and convert them into visible light (Figure 15). Converting $\mathbf{x}$-rays into photons and counting them with a photomultiplier provide a more efficient way to detect radiation.

Camera-scintillator radiography has been used at Lawrence Livermore National Laboratory (LLNL) as well as in industries for various applications. LLNL used glass plates as scintillators for applications such as pit inspections and bridge pin inspections [31,33]. Lockheed Missiles \& Space Co. developed a semi-automated high resolution digital real-time 
radiographic (HRRTR) inspection system to inspect aircraft structures and composite materials (Figure 16). This system uses fiber optic scintillators to convert the $\mathrm{x}$-ray image into an optical image. The image is then displayed electronically on a monitor. The advantage of using optical fibers as scintillators over phosphor screens is that optical fibers provide higher resolution due to better light collimation through the $10 \mu \mathrm{m}$ fibers. This system has better spatial resolution and higher sensitivity than an image intensifier system (Figure 17) and better dynamic range than $x$ ray film [27].

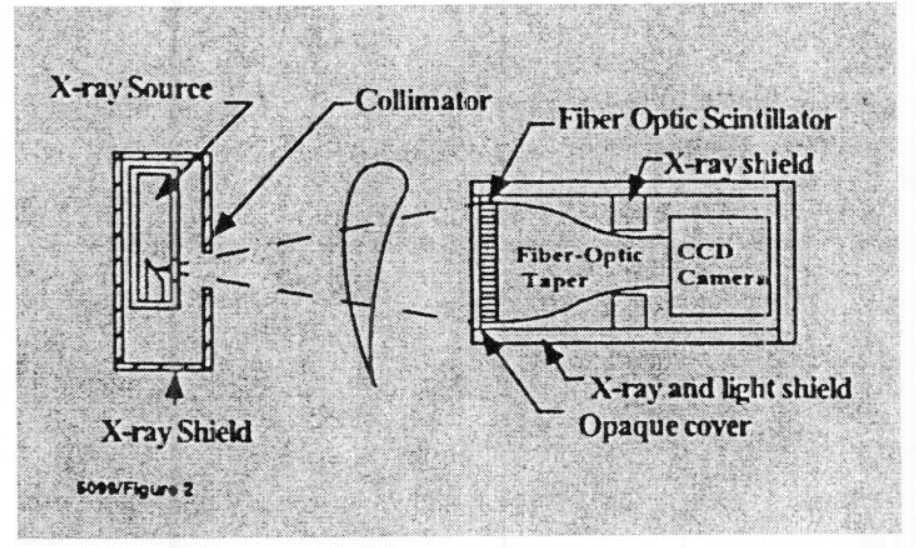

Figure 16. Schematic of HRRTR system [30]

\section{Image intensifier}

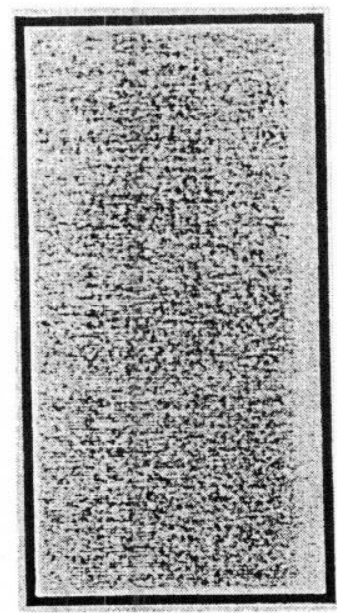

Figure 17. X-ray image of 0.01 in. aluminum, improvements seen with new HRRTR system [30]

Advantages of radiography include its ability to access a wide range of thickness. It is possible to retain permanent results using photographic film and real-time viewing using appropriate instrumentation. Complex objects that may be too difficult to scan with ultrasonics can be inspected using radiography.

One disadvantage of radiography is that unlike ultrasonics, its sensitivity decreases with increasing thickness of the part. Access to both sides of the object is required. The $\mathrm{x}$-ray beam must be oriented parallel to the cracks, which means that a series of tangential shots must be taken around the circumference in order to inspect the entire vessel. This might be a problem depending on the access to the vessel and the time required to take all these shots. Since delamination does not change the $\mathrm{x}$-ray density of the material, radiography is unable to detect this kind of defect. In fact, in many cases, radiography was unsuccessful in detecting damage in composites [49]. The equipment and instrumentation for radiographic applications are very expensive, and radiation is a serious health hazard to the personnel.

It would be convenient to use radiography to inspect the composite firing vessel since radiographic cameras would already be set up for the explosive testing. The camera-scintillator 
method shows some promise if it is possible to embed optical fibers in the composite laminates and use the light output from the fibers to determine if the fibers have been damaged. However, more research needs to be done to investigate this possibility. Like all other localized techniques, radiography needs to be complemented by a global technique in order to increase its efficiency.

Eddy Current $[1,3-6,8,9,12]$

The eddy current technique detects flaws using induced alternating current. Electric current flowing in a wire generates a magnetic field around the wire, which is always perpendicular to the current. Eddy current is the induced alternating current that flows in closed paths perpendicular to the magnetic field. Due to mutual induction, the eddy current will then affect the current in the induction coil, changing the impedance of the coil. The phase and magnitude of the eddy current are influenced by the electrical conductivity, the magnetic permeability, the mass, and the discontinuities in the conductor (Figure 18).

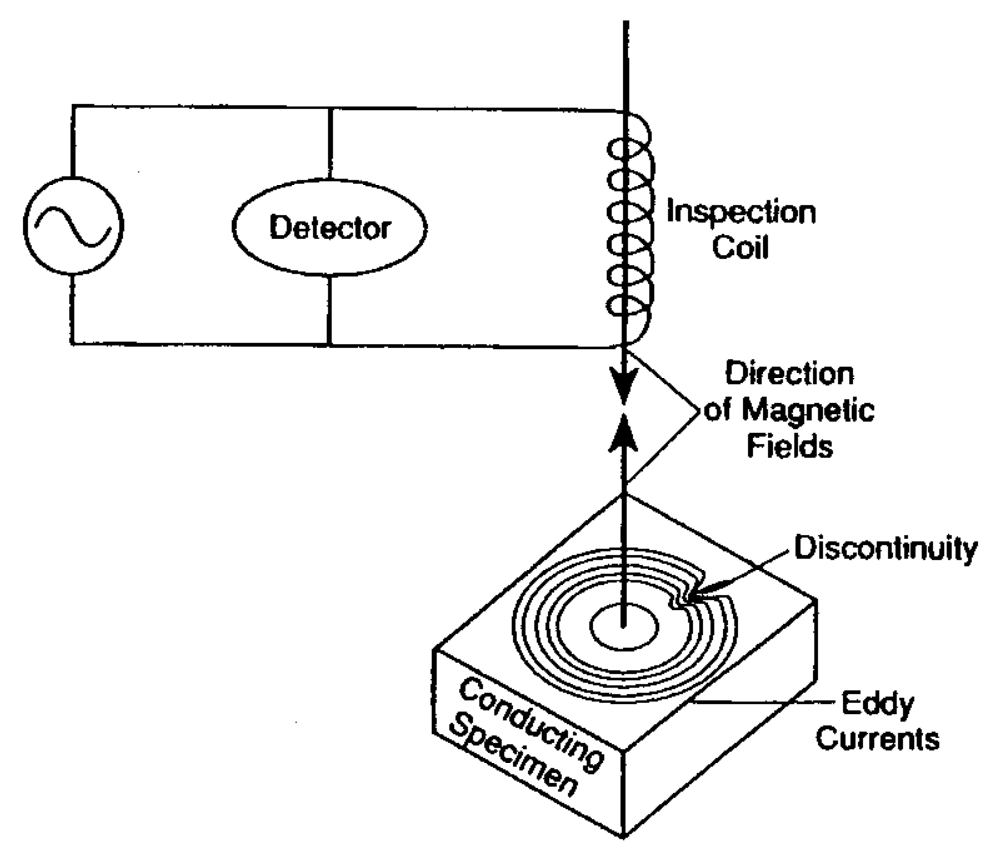

Figure 18. Schematic of eddy current test. A crack in the object changes the eddy current and induced magnetic field [6]

Eddy current is only applicable to electrically conductive materials. In fact, the method works best on material with high conductivity. Eddy current has the ability to detect surface and near surface discontinuities and measure their depths. It is most effective on thin and small items, and its sensitivity decreases when detecting flaws far beneath the surface. Discontinuities are best detected if the flow of the eddy current is close to being perpendicular to the flaw. The eddy current method can measure cracks up to 0.2 millimeter in length [12].

Basic components of eddy current include an oscillator for generating alternating current. Test coils can be combined induction-receiving, where the same coil generates the magnetic field and detects the impedance change, or separate induction-receiving, where the induced magnetic 
field is measured by a different coil. The shape of the coil is dependent on the purpose of the test as well as the shape of the object being tested. Short coils are more sensitive than long coils and therefore, better for detecting small discontinuities. A means of measuring the impedance change in the coil is also needed. The impedance testing technique uses a bridge circuit to measure the magnitude of the impedance with no phase change. When inspecting a surface without a defect, there is no signal through the meter. If a defect is present, the bridge is unbalanced, and an output voltage exists across the meter. Using the impedance plane method, the signal from the excitation coil is resolved into the resistive and reactance components and displayed on an oscilloscope. The displacement of the impedance vector indicates whether a defect exists. Finally, a medium to display the information is needed. This can be meters, cathode ray tubes, or oscilloscopes, depending on the methods used.

While most composites are poor conductors of electricity, some of the carbon fibers are relatively good conductors. Therefore, eddy current can be applied to monitor fiber orientation and detect fiber breakage in these carbon fibers [9]. However, eddy current probes at standard inspection frequencies $(<1 \mathrm{MHz})$ are unable to detect changes in graphite fiber [18]. Inspection of thick composites is ineffective using eddy current testing.

Advantages of eddy current testing include the ability to perform the test quickly. The process can be automated for high speed testing, and the instrumentation is relatively low cost. Mechanical contact between the eddy current transducers and the test object is not needed. However, the probe must be located near the surface of the object. Inspection depth can be controlled by adjusting the frequency of the energizing current. Increasing the frequency decreases the penetration depth but also increases the sensitivity to flaws.

Perhaps the biggest disadvantage to eddy current testing is that it is only limited to electrically conductive materials, which does not include most composites. It is also limited by its low penetration power, which means that only thin materials or near-surface flaws can be inspected. Eddy current does not provide any quantitative indications of the discontinuities. Finally, data interpretations can be complicated due to different material, geometric, and electronic parameters.

Since eddy current testing can only be applied to ferromagnetic materials, it cannot be used to inspect Kevlar and all other composites excluding graphite fibers. However, eddy current is a possible choice for monitoring the aluminum liner. In this case, the eddy current probes should be placed on the inside of the vessel.

Embedded Fiber Optic Sensors [7, 37, 40, 44]

Introduction to Fiber Optics

An optical fiber is consisted of three different layered cylinders of glass or plastic. The innermost layer is called the core (3-100 $\mu \mathrm{m}$ in diameter), and it is usually made of silica glass. Surrounding the core is a dielectric material, called the cladding, whose diameter is typically 125 
$\mu \mathrm{m}$. The outermost layer is the jacket or the buffer. This 250 or $900 \mu \mathrm{m}$ diameter plastic cylinder protects the fiber from damage or moisture absorption and gives the fiber its mechanical strength (Figure 19).

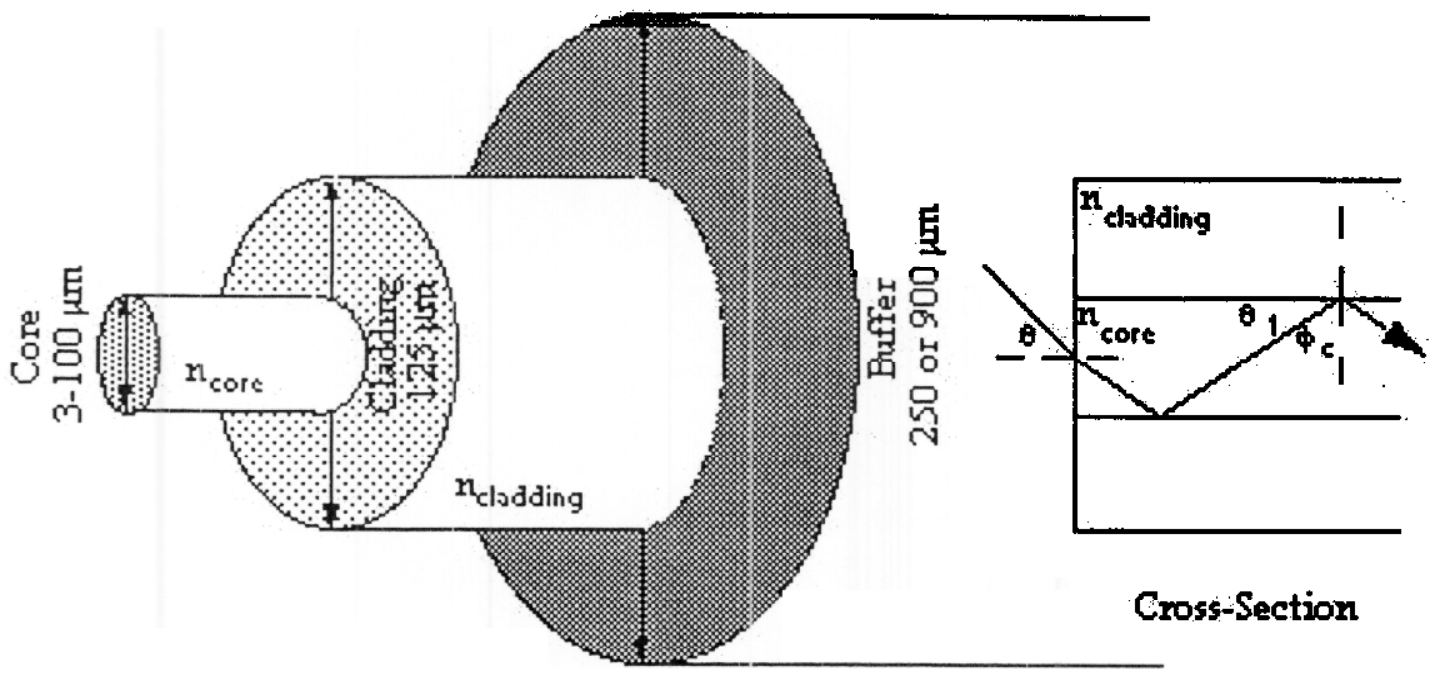

Figure 19. Cross sectional view of typical optical fiber [44]

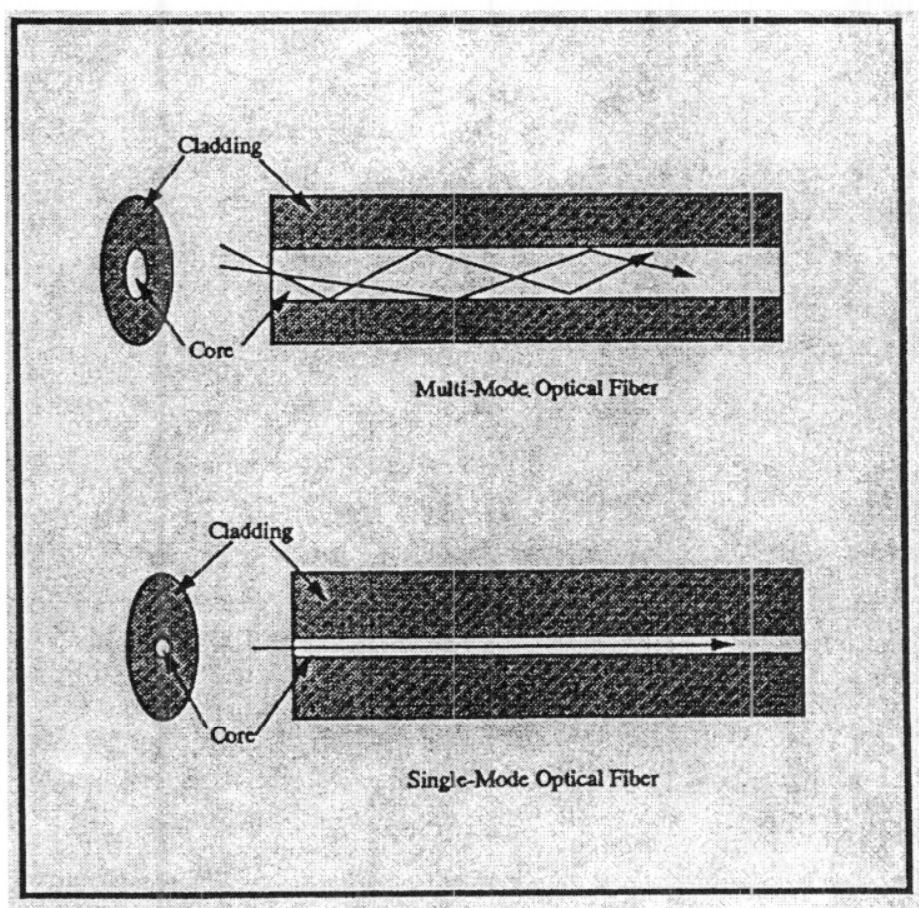

Figure 20. Light transmission through single-mode and multi-mode fibers [7]
Light propagates along the length of the fiber due to Snell's law of total internal reflection. Since the index of reflection of the cladding is less than that of the core, a light beam striking the interface between the core and the cladding at an angle greater than the critical angle is reflected back to the core again. Light continues to travel along the fiber in this manner until it encounters a disturbance along the fiber, which changes the characteristics of the light beam. These characteristics include amplitude, polarization, phase, wavelength, time of flight, and modal distribution. Monitoring the changes in the characteristics of the light beam provides information on the disturbance on the fiber. Numerous parameters, such as strain, temperature, pressure, load, acoustic emission, damage, cracking, and chemical composition, can be detected by analyzing the different characteristics of 
the light beam. Single-mode fibers provide a light path for a single light ray, whereas multimode fibers consist of multiple light paths (Figure 20). The number of paths is determined by factors such as the characteristics of the light injected into the fiber, the diameter of the fiber, and the chemical composition of the fiber.

\section{Classification of Fiber Optic Sensors}

Fiber optic sensors are divided into two classes - extrinsic and intrinsic. In an extrinsic device, guided light exits the fiber, interacts with the environment and modulated by the environmental effects, and re-enters the fiber. Propagating light in an intrinsic device remains within the fiber along its entire length, so the light is actually modulated within the fiber. Intrinsic fiber optic sensors are generally simpler and easier to embed.

Intensity based sensors are the most rugged and least sensitive type of sensors. The intensity of light that appears at one end of an optical fiber is the signal that corresponds to the physical quantity being measured. The change in the intensity of light may affect the time-offlight, refractive index, amplitude, and wavelength. These sensors have the advantages of being simple, inexpensive, and easy to build. However, they are very noisy and unreliable since many different physical factors can cause a change in the intensity of the light beam $[34,44]$.

Interferometric sensors are the most sensitive but least rugged. These sensors generally detect the changes in the phase of the light beam that exits two single mode fibers. This phase change is caused by the effects that the environment has on the fibers. Interferometric sensors are most often used in applications that require local measurements, but it may be possible to have sensors that are up to 1 meter long. Inteferometric sensors include Mach-Zehnder, Michelson, Fabry-Perot fiber optic sensors, and Bragg grating sensors [10, 34, 44, 54].

Polarimetric sensors are more sensitive than intensity sensors but more rugged than interferometric sensors. These sensors also have longer sensor gauge lengths than interferometric sensors. The underlying principle of polarimetric sensors is the interference pattern of two light beams passing through the same path. External influences would affect both beams equally [44]. In Asundi's [34] experiment, circular polarized light is coupled into an optical fiber. The light output from the fiber is collimated and passed through a polarization beam splitter, and each beam is detected with a photodiode. Defects affect the load required to produce a given phase change of the sensor output. Asundi showed that varying the length of delamination, the location of delamination, and the location of fiber breakage all had an effect on the load that was required to produce a given phase change of the light beam (Figure 21) [34]. Disadvantages to polarimetric sensors include expensive equipment and instrumentation, complex systems, and high sensitivity to temperature. 


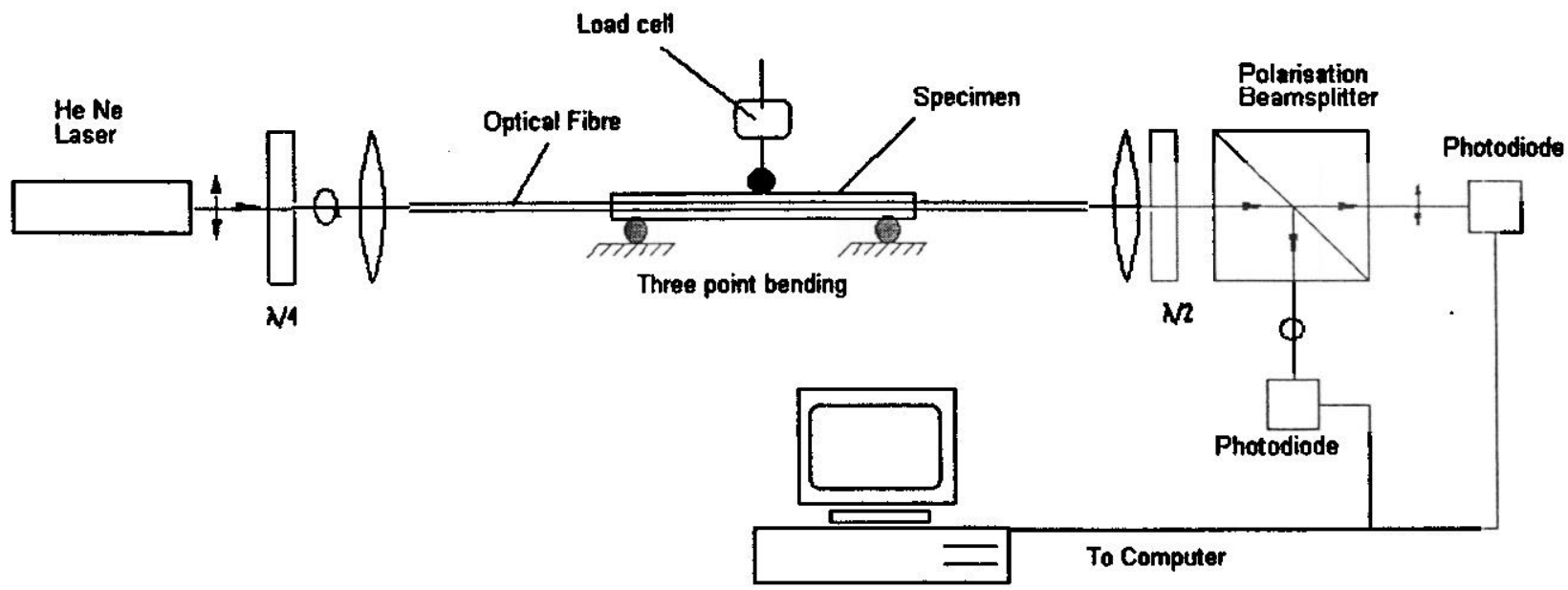

Figure 21. Asundi's polarimetric fiber optic sensor experimental set-up [31]

\section{Types of interferometric fiber optic sensors}

Mach-Zehnder strain sensors $[7,10]$

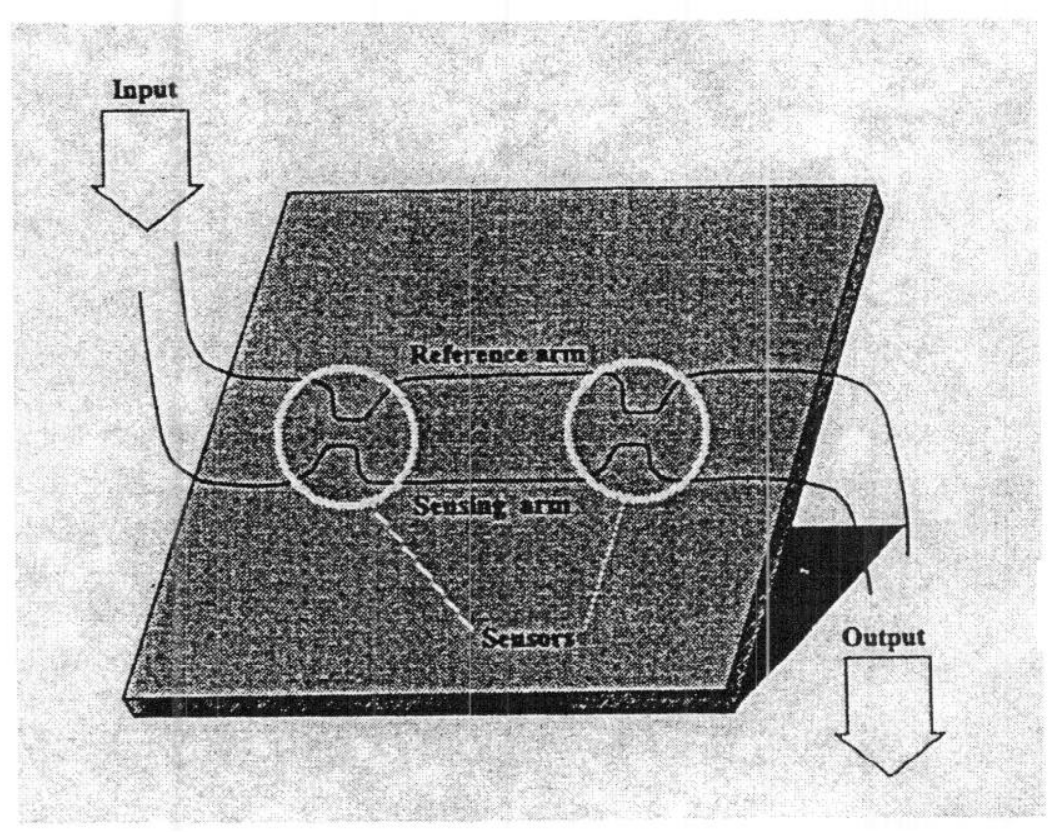

Figure 22. Mach-Zehnder sensing configuration [7]
A Mach-Zehnder strain sensor is consisted of two adjacent single mode optical fibers. The longer fiber functions as a reference arm, which is protected from all external stimuli. Light beam traveling through this fiber will not be altered in any way. The shorter fiber, called the sensing arm, is subjected to mechanical deformation, which changes the optical path length of the light beam. Changes in length and refractive index of the sensing fiber produce a phase shift in the two light beams. By observing the shift in fringe pattern, one can determine the phase shift and obtain information about the deformation on the fiber (Figure 22). These strain sensors are extremely sensitive. They can detect movements in the fibers as small as $10^{-3}$ meters. 


\section{Michelson strain sensors $[7,10]$}

The Michelson strain sensor is similar to the Mach-Zehnder sensor except that the Michelson uses two optical fibers with mirrored ends to reflect the light back through the fibers and coupler to a detector, which then detects the phase shift (Figure 23). The Michelson system has less of an effect on the host material. It is also more sensitive since its light path is twice as long. However, this type of sensor suffers from noise due to feedback into the laser when the light beam travels back through the coupler.

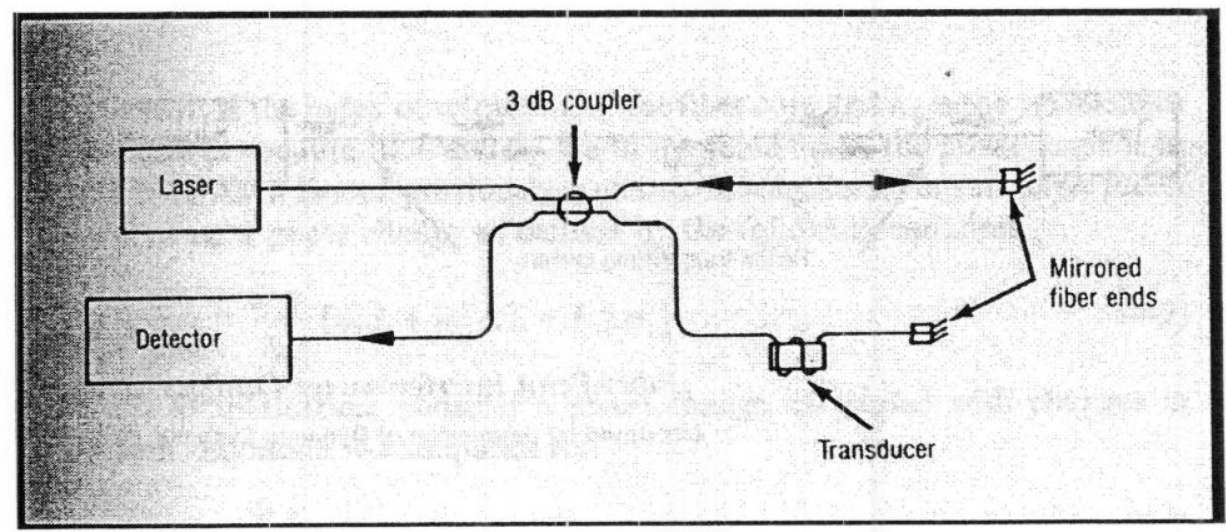

Figure 23. Michelson strain sensor configuration [10]

Fabry Perot strain gauges $[10,36,42]$

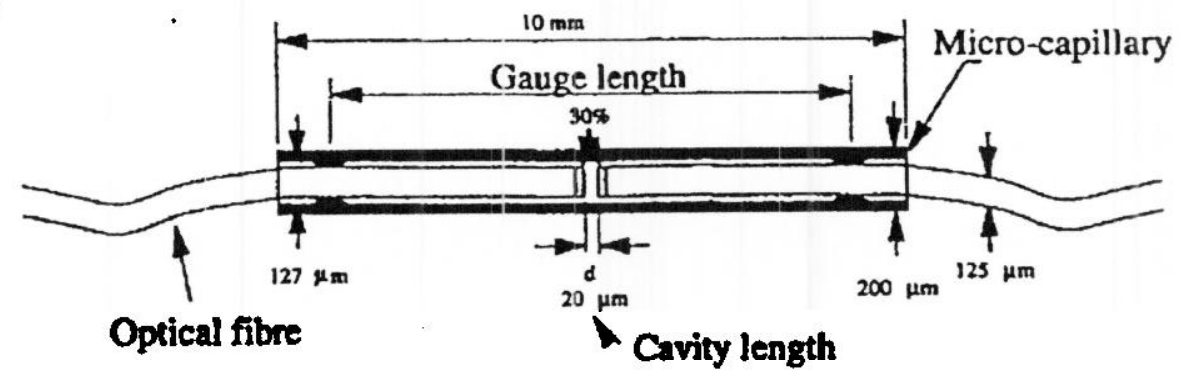

Figure 24. Fabry-Perot strain gauge [36]

Unlike the Mach-Zehnder and Michelson strain sensors, the Fabry-Perot does not involve a reference fiber. A Fabry-Perot strain gauge is consisted of two multimode optical fibers welded into a microcapillary. Two mirrors, facing each other, are located on each end of the 
fibers and separated by a distance called the cavity length (Figure 24). The wavelength of the reflected light varies according to the cavity length. The strain in the fiber is transferred to the gauge, which causes a change in the cavity length. This strain can then be calculated from the following equation:

$$
\text { Strain }=\frac{\Delta \mathrm{L}_{\text {Cavity }}}{\text { L }_{\text {Gauge }}}
$$

where $\mathrm{L}_{\text {Gauge }}=$ gauge length, the distance between the 2 welded spots of the microcapillary

Fabry-Perot strain gauges are ideal for making strain measurements. They can measure the cavity length with a precision of $0.001 \mu \mathrm{m}$ and offer a resolution of $0.01 \%$ strain range [42]. These strain gauges offer the unique advantage of being able to compensate for thermal expansion by replacing one of the optical fibers with a metallic fiber. If the gauge is strained mechanically, the cavity length will change in accordance to the above equation. However, if the gauge is elongated or compressed due to thermal effects, the cavity length will not change. These strain gauges can be embedded within layers of composites or merely mounted on the surface of the object. In general, Fabry-Perot strain gauges are twice as sensitive as the other interferometric sensors.

\section{Bragg grating sensors}

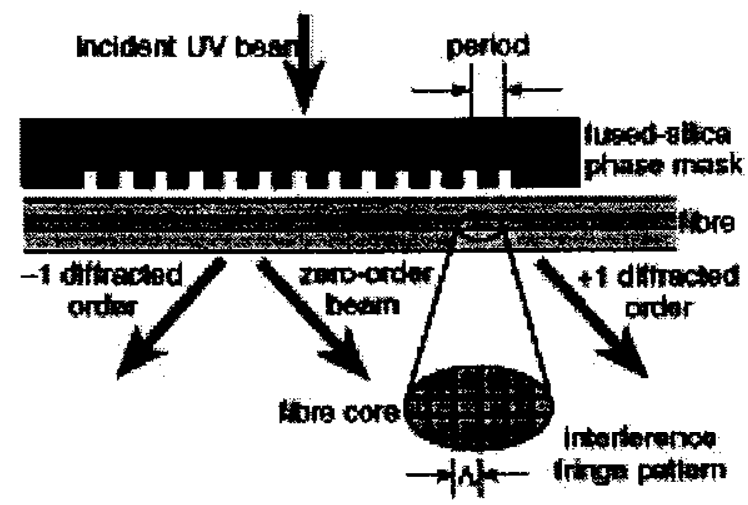

Figure 25. Bragg grating written into an optical fiber by shining laser through a phase mask [50]
Bragg grating sensors consist of Bragg gratings, which are periodically varying refractive index gratings, usually about 0.3-10 $\mathrm{cm}$ in length. The typical fabrication steps are as follow: 1) remove polymer jacket, 2) expose the fiber to a periodic pattern of ultraviolet light, 3) anneal the fiber grating with heat, and 4) recoat the stripped fiber region with a protective plastic coating [53]. Absorption of ultraviolet (UV) light into the fiber changes the chemical bonds in the glass, which causes a change in the index of refraction of the glass (Figure 25). The reflection bandwidth and Bragg wavelength are determined by the period and length of the phase mask and the

exposure time. Touching the bare fiber or using excessive UV intensity can weaken the strength of the fiber. An alternative process was suggested by Starodubov [53] to produce stronger fiber gratings. This process involves writing the fiber grating directly through the polymer coating using a special coating that is transparent to UV writing wavelength. The advantages of this process are that it simplifies the fabrication process, reduces the grating cost, decreases the 
probability of the fiber damage, and produces strong grating since the fiber is never exposed to the environment [53].

Bragg grating fibers can be configured as strain gauges by coupling the core of the fiber to the material that is being tested. Lines in the grating reflect light in the fiber if their period matches the wavelength of the light. This reflected wavelength is called the Bragg wavelength. The Bragg wavelength is defined by the equation:

$$
\lambda_{\mathrm{B}}=2 \mathrm{~nL}
$$

where

$$
\begin{aligned}
& \lambda_{B}=\text { Bragg wavelength } \\
& n=\text { effective index refraction of the fiber } \\
& L=\text { grating period }
\end{aligned}
$$

When stress on the fiber bends the grating, the distance between the lines increases or decreases, causing the wavelength reflected by the grating to change proportionally. The strain in the fiber can be determined by measuring the change in the Bragg wavelength and then calculated using the following equation:

$$
\frac{\Delta \lambda_{\mathrm{B}}}{\lambda_{\mathrm{B}}}=(1-\mathrm{P}) * \frac{\Delta \mathrm{L}}{\mathrm{L}}
$$

where $\mathrm{P}=$ optical strain coefficient (typically 0.22 for axial strain)

$\mathrm{L}=$ length of the sensor [40]

A major concern with optical fibers is their mechanical strength. If embedded in the structure, it is very important that the optical fiber does not break before the host material fiber does. The maximum strain level for Kevlar 49 is $3-4 \%$, for pristine fiber is $5-6 \%$, and for optical fibers with sensors is $3-4 \%$ [46, 52]. Even more encouraging is that work done by Matthewson [53] showed that that there is no difference in mechanical strength between pristine fibers and fibers with Bragg grating [53].

Bragg grating sensors are one of the newest and most popular techniques for strain measurements. They are extremely sensitive, able to measure within $0.1 \mu \mathrm{e}$ for strain and $0.1^{\circ} \mathrm{C}$ for temperature [44]. They can easily be multiplexed, which means writing multiple gratings along one fiber so that multiple point measurements can be made. Multiplexing is most commonly achieved by wavelength division, where each sensor is assigned to its own distinct reflection wavelength, making it different from the other sensors in the fiber. However, it is also possible to multiplex sensors in the time domain by utilizing differences in propagation delays, or the coherence domain by matching white-light interferometers. When an array of sensors is used, each sensor is read by cycling through each array with an optical switch [38]. Depending on the system, sensors can be spatially located at any distance from each other, anywhere from mm's to km's [52]. A holographic technique is developed at Southampton University [38] for 
writing arrays of gratings during the pulling of the fiber. This technique improves the cost and speed of the production as well as dramatically improves the mechanical strength of the gratings [38]. Another advantage of Bragg grating sensors is their insensitivity to noise disturbance due to the direct encoding of the sensed information into wavelength, which is an absolute parameter [40].

Work was done to test the ability of embedded Bragg grating strain sensors to accurately monitor filament wounded pressure vessels during pressurization and impact damage. Four 5.75 " diameter carbon/epoxy filament wounded bottles were monitored with four surface mounted resistance strain gauges and a 4 by 4 matrix of embedded Bragg grating strain sensors. During pressurization of the bottles, the Bragg grating sensors responded differently based on their direction and location within the bottle. The agreement between the resistance strain gauges and the Bragg grating strain gauges was best for sensors embedded in the hoop direction at mid-cylinder and worst for the helical direction in the tangential area. However, the overall data obtained from the embedded strain gauges matched those from the resistance strain gauges and computer models. As for the impact tests, the embedded strain gauges were able to detect damage anywhere within two inches of their placement regardless of the how the sensors or fibers were oriented [43].

Smart Fibres Ltd. [50] developed an optical strain sensor system that utilizes Bragg grating sensors to measure strain in a structure. This system has been applied to maritime, aerospace, civil, and offshore structures and is expected to last for the complete lifetime of the structure. The data acquisition unit is able to monitor 8 fibers with 50-100 sensors in parallel. These sensors can be located along the fiber at any distance from each along. This is a point measurement system, which measures strain at specific points along the fiber. It is also limited to strain measurements in the axial direction, which means that during the embedding process, the sensors must be placed in the direction of the desired measurement [50-52].

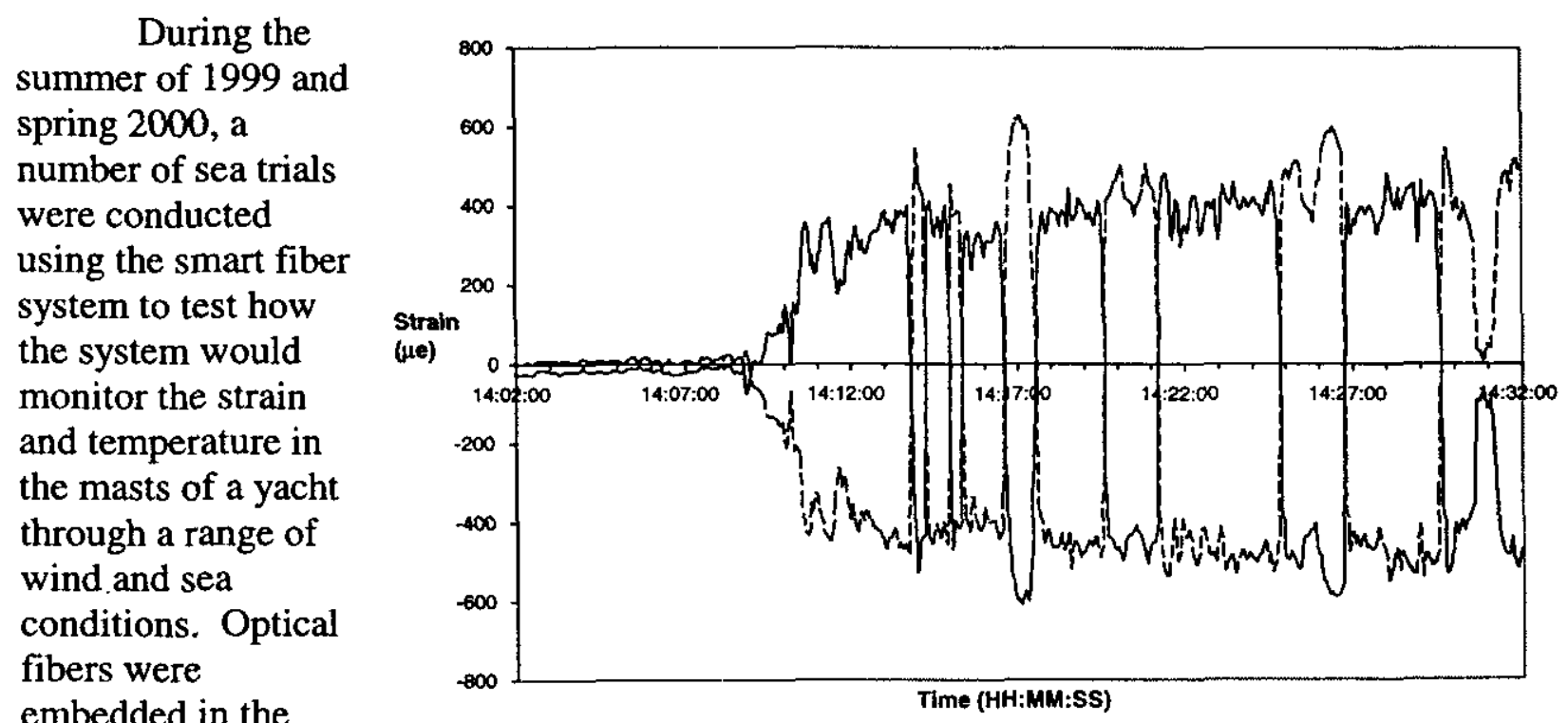

embedded in the

Figure 26. Strain profile data shows the effects of the mast and boom of a yacht. Figure 26 shows the strain wind on the masts [39] 
profile obtained from two sensors in the same position on opposite sides of a mast. The strain profile correlates with the response of the mast to the wind during the course of a trial. The mainsail and jib were hoisted at 14:09 and 14:10 respectively, resulting in the increase in strain. The yacht then undergoes a series of tacks. The data also reveals when the yacht changed its side to the wind (when the strain changes from tensile to compression and vice versa - at $14: 13: 40,14: 14: 20,14: 14: 55, \ldots)$. Computer modeling was used to verify the accuracy of the experimental data [39].

\section{$\underline{\text { Evaluation of Fiber Optic Sensors }}$}

Embedded fiber optic sensors offer many advantages. Their small physical size and lightweight minimize the effect that they would have on the structural integrity of the host material. Their mechanical flexibility enables them to be applied to complex surfaces and areas that are difficult to reach. The sensors are very robust, enabling them to survive hostile environments. Strain measurements can be made within an accuracy of $0.1 \mu \mathrm{e}$. Sensing multiple parameters is also possible by monitoring various characteristics of the light beam. Much like surface mounted strain gauges, embedded fiber optic sensors monitor the system in real-time. However, they have several important advantages over surface mounted strain gauges. Embedded fiber optic sensors are immune to electromagnetic interference even in electrically noisy environments. Their ability to be embedded within layers of composite laminates enables regions throughout the thickness of the structure to be monitored. Finally, these sensors are extremely compatible with composites. Optical fibers and composites are comparable in strength (described in Bragg grating sensors section) and size. The yarn size of Kevlar fibers varies depending on the number of filaments. During filament winding, the yarns become flattened into ribbons, with a thickness of about 254 microns [55]. Since a typical coated optical fiber has a diameter of about 250 microns, the ribbon thickness of Kevlar fibers and the size of optical fibers are essentially the same. Similar mechanical properties and size minimize the effect that the optical fiber would have on the composites. Research also indicates that embedded fiber optic sensors have no effect on the fatigue life of composites under compression and tensile loading [32].

The disadvantages of embedded fiber optic sensors are few compared to their advantages. Since these sensors cannot be repaired, once they are damaged, that portion of the optical fiber is rendered useless. The fiber embedding process may be limited by the properties of the fiber, the properties of the host material, and the processing conditions required for material fabrication. There may also be a need to isolate the sensors from unwanted parameters. Certain applications may be limited by the availability of the optical source. One primary concern is the effect that sensors might have on the host material. Research is currently being done to address this concern. The work is still in its preliminary stage since the result is affected by many factors, such as the location and the orientation of optical fibers and the characteristics of the host material. However, preliminary work shows that the strength of the host material is unaffected by the embedded optical fibers [7]. Finally, since embedding fiber optic sensors is a relatively novel idea, there is a general low awareness of this technology and many aspects of it are not well understood and developed. 
Embedded fiber optic sensors is an attractive technology with a very promising future. Much research is currently being done to better understand the optical fibers and improve their capabilities. Giles [45] reported that it is possible to use the whole length of the optical fiber as a sensor using a single mode, birefringent fiber. The position of the disturbance along the fiber can be located by measuring the time delay of the signal. Further work is being done to develop a fully automated multi-purpose damage detection system using fiber optic sensors [45]. Another area of research is the ability to detect delamination in fibers without the sensors having to be located directly over the region of delamination [41]. Investigations on rules for embedding optical fibers within layers of cornposites are currently being pursued [48]. More algorithms are being studied in the areas of sensing multi-parameters and making distributed measurements [38]. Fibers with multiple overlapping gratings were developed to respond to strain in multi-directions [47].

\section{CONCLUSION}

Based upon the current knowledge and the resources available to the author, embedded Bragg grating fiber optic sensors appear to be the most promising technique with regards to monitoring the integrity of the composite firing vessel. Embedded fiber optic sensors offer some unique advantages that most other methods do not have. They are extremely compatible with composites. Current research shows that embedded sensors have little or no structural and mechanical effects on the host material. These sensors can also easily be embedded within layers of composites during the fabrication of the vessel. As the vessel is being wrapped with Kevlar, one can conceivably substitute one of the spools of Kevlar with a spool of optical fiber. Embedding the sensors allows all regions of the vessel to be monitored in real-time. Finally, embedded fiber optic sensors are immune to electromagnetic interference unlike techniques such as surface mounted strain gauges and acoustic emission. This greatly simplifies the interpretation of the results. The ability for the sensors to be multiplexed also substantially enhances its capabilities. Since these sensors can be separated by any distance, this feature allows the system to be customized for the needs of the vessel.

None of the other techniques investigated can independently monitor the vessel [Table 2]. However, multiple techniques can be used to efficiently assess the vessel. Global techniques enable large structures to be inspected quickly in order to locate possible areas of defects. Localized techniques can then be applied to characterize the defects. Based on present knowledge, both thermography and acoustic emission appear inadequate to provide reliable results for global monitoring of the vessel. Thermography is ineffective in inspecting thick composites, and the background noise of acoustic emission produces very unreliable signals. As for localized techniques, both radiography and ultrasonic testing show some promise. However, the efficiency and reliability of both of these techniques are questionable. 


\begin{tabular}{|c|c|c|c|c|c|c|}
\hline & \multicolumn{4}{|c|}{ FLAW TYPE } & \multicolumn{2}{|c|}{ APPLICATIONS } \\
\hline & Delamination & $\begin{array}{l}\text { Matrix } \\
\text { cracks }\end{array}$ & $\begin{array}{c}\text { Fiber } \\
\text { breaks }\end{array}$ & $\begin{array}{l}\text { Impact } \\
\text { damage }\end{array}$ & Material & $\begin{array}{l}\text { Features } \\
\text { \& Forms }\end{array}$ \\
\hline $\begin{array}{c}\text { Visual } \\
\text { Inspection }\end{array}$ & \multicolumn{3}{|c|}{$\begin{array}{l}\text { Only if defects appear on the surface of the } \\
\text { object }\end{array}$} & 3 & All material & $\begin{array}{l}\text { Surfaces } \\
\text { only }\end{array}$ \\
\hline $\begin{array}{c}\text { Liquid } \\
\text { Penetrant }\end{array}$ & $\begin{array}{l}\text { Only if done } \\
\text { from the side of } \\
\text { the panels }\end{array}$ & \multicolumn{3}{|c|}{ Only if located on the surface } & $\begin{array}{c}\text { All } \\
\text { nonporous } \\
\text { material }\end{array}$ & $\begin{array}{c}\text { Surfaces } \\
\text { only }\end{array}$ \\
\hline $\begin{array}{l}\text { Magnetic } \\
\text { Particles }\end{array}$ & \multicolumn{4}{|c|}{$\mathbf{N} / \mathbf{A}$} & $\begin{array}{l}\text { Ferro- } \\
\text { magnetic } \\
\text { materials }\end{array}$ & $\begin{array}{c}\text { Surface \& } \\
\text { near surface } \\
\text { Regular/ } \\
\text { uniform } \\
\text { shapes } \\
\end{array}$ \\
\hline $\begin{array}{c}\text { Surface } \\
\text { mounted } \\
\text { strain gauges }\end{array}$ & \multicolumn{4}{|c|}{ only if strain gauge is directly over region } & $\begin{array}{c}\text { Metal } \\
\text { Nonmetal } \\
\text { Composites }\end{array}$ & $\begin{array}{c}\text { Surfaces } \\
\text { only }\end{array}$ \\
\hline $\begin{array}{l}\text { Thermal } \\
\text { Testing }\end{array}$ & $\begin{array}{c}2 \\
\text { best for shallow } \\
\text { delaminations; } \\
\text { limited for deep } \\
\text { ones } \\
\end{array}$ & \multicolumn{2}{|c|}{ N/A } & 2 & $\begin{array}{c}\text { Metal } \\
\text { Nonmetal } \\
\text { Composites }\end{array}$ & Sub-surfaces \\
\hline $\begin{array}{l}\text { Acoustic } \\
\text { Emission }\end{array}$ & 3 & 2 & 2 & 3 & $\begin{array}{c}\text { Metal } \\
\text { Nonmetal } \\
\text { Composites }\end{array}$ & $\begin{array}{l}\text { Entire } \\
\text { objects }\end{array}$ \\
\hline $\begin{array}{c}\text { Ultrasonic } \\
\text { Testing }\end{array}$ & 1 & \multicolumn{2}{|c|}{ N/A } & $\mathbf{1}$ & $\begin{array}{c}\text { Metal } \\
\text { Nonmetal } \\
\text { Composites } \\
\end{array}$ & $\begin{array}{l}\text { Surface/ } \\
\text { Internal }\end{array}$ \\
\hline Radiography & $\begin{array}{c}\text { N/A } \\
\text { Detectable in } \\
\text { very rare cases }\end{array}$ & 2 & 1 & $\mathbf{N} / \mathbf{A}$ & $\begin{array}{c}\text { Metal } \\
\text { Nonmetal } \\
\text { Composites }\end{array}$ & 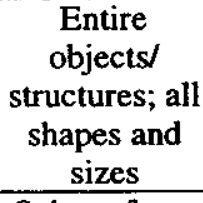 \\
\hline Eddy Current & \multicolumn{2}{|c|}{ N/A } & 1 & 2 & $\begin{array}{l}\text { Metal alloys; } \\
\text { electro- } \\
\text { conductors }\end{array}$ & $\begin{array}{c}\text { Sub-surfaces } \\
\text { regular \& } \\
\text { uniform } \\
\text { shapes } \\
\end{array}$ \\
\hline $\begin{array}{l}\text { Embedded } \\
\text { Fiber Optic } \\
\text { Sensors }\end{array}$ & \multicolumn{4}{|c|}{ only if sensing portion is directly over region } & $\begin{array}{c}\text { Metal } \\
\text { Nonmetal } \\
\text { Composites }\end{array}$ & Any region \\
\hline
\end{tabular}

Table 2. Rating of nondestructive methods with respect to ability to detect each flaw type in composite materials as well as their applications to types and features of materials

1 Good sensitivity and reliability. Good candidate for primary method

2 Less reliability or limited applicability. May be good backup method

3 Limited applicability. May provide some useful information

N/A Not applicable for this technique 


\section{RECOMMENDATIONS}

This report merely lays the groundwork for more research. The question of how to monitor the structural integrity of the composite firing vessel and determine when it should be retired cannot be answered until more information is provided. Recommendations for future work include:

- Determine the failure mode(s) of the vessel

Without testing the vessel and determining its failure mechanisms, it is difficult to narrow down the possibilities any further.

- Continuing investigation of techniques used in research centers and industries It is extremely important to be informed of new technologies in order to find the best match for the vessel.

- Research the option of using camera-scintillator radiography As mentioned in the radiography section, perhaps optical fibers embedded within layers of composites can function as scintillators for radiographic applications. Optical fibers can convert $x$-rays into visible light, and by observing the output light beam, one can locate regions of defects. However, more research needs to be done to better understand this technology.

- Gather information on new fiber optic sensor research

- Continue correspondence with Smart Fibers Ltd.

As more information about the vessel becomes available, more specific inquiries about the smart fibers system are needed in order to determine if this system will suit our needs.

- Research methods that can be used in monitoring the aluminum liner

Due to the limited time, not much research was done in investigating diagnostic methods for the liner.

- Test the applicability of the techniques discussed by using them to monitor prototype vessels

It is extremely valuable to be able to determine whether these techniques would work by testing them. For the first half scale prototype that already has been fabricated, it is too late to embed fiber optic sensors in them. However, acoustic emission can be used to monitor the vessel during the tests. Radiography, ultrasonics, and thermography can be applied afterwards to detect flaws. Since embedded fiber optic sensors appear to show the most promise, it is crucial to actually test this technology on future prototype vessels. Systems should be built into ongoing prototype development vessels to investigate their effectiveness resulting from dynamic testing. 


\section{REFERENCES}

BOOKS (not available in pdfformat)

1. Advanced Composites Design Guide, Vol. 3, $3^{\text {rd }}$ ed. Air Force Flight Dynamics Laboratory (FBC), Wright-Patterson Air Force Base, Ohio 45433 (limited distribution to U.S. Government agencies only), 1977. Sec 3.2.2.4.

2. Boving, Knud G., ed. NDE Handbook: Non-destructive examination methods for condition monitoring. Butterworths: Boston, 1989.

3. Bray, Don E. and Don McBride, ed. Nondestructive Testing Techniques. John Wiley \& Sons, Inc., New York, 1992.

4. Bray, Don E. and Roderick K. Stanley. Nondestructive Evaluation: A Tool in Design, Manufacturing, and Service, rev ed. CRC Press, Inc: Boca Raton, 1997.

5. Blitz, Jack. Electrical and Magnetic Methods of Nondestructive Testing. Adam Hilger: Bristol, 1991.

6. Cartz, Louis. Nondestructive Testing. A.SM International: U.S., 1995.

7. Gandhi, M.V. and B.S. Thompson. Smart Materials and Structures. Chapman \& Hall: London, 1992.

8. Hyber, Oren J., ed. Introduction to Nondestructive Testing. American Society for Metals and Metals Engineering Institute, 1997.

9. Jones, Thomas S. and Harold Berger. "Nondestructive Evaluation Methods for Composites." Lee, Stuart M., ed. International Encyclopedia of Composites, Vol. 4. VCH Pusblishers, Inc., New York, 1991.

10. Kron, D. A. Fiber Optic Sensors: Fundamentals and Applications, $2^{\text {nd }}$ ed. Instrument Society of America: Research Triangle Park, 1992.

11. Maldague, Xavier P. V., ed. Infrared Methodology and Technology. Gordon and Breach Science Publishers: Amsterdam, 1994.

12. McIntire. Paul, ed. Nondestructive Testing Handbook, Vol 3, Radiography and Radiation Testing. $2^{\text {nd }}$ ed. American Society for Nondestructive Testing, Inc: U.S., 1985.

13. McIntire. Paul, ed. Nondestructive Testing Handbook, Vol 5, Acoustic Emission Testing, $2^{\text {nd }}$ ed. American Society for Nondestructive Testing, Inc: U.S., 1987. 
14. McIntire. Paul, ed. Nondestructive Testing Handbook, Vol 7, Ultrasonic Testing. $2^{\text {nd }}$ ed. American Society for Nondestructive Testing, Inc: U.S., 1991.

15. Morgan, Roger J. and Ronald E. Alred, "Aramid Fiber Composites." Lee, Stuart M., ed. International Encyclopedia of Composites, Vol. 1. VCH Pusblishers, Inc., New York, 1990. pp. 37-54.

16. Schwartz, Mel M. Composite Materials, Volume I: Properties, Nondestructive Testing, and Repair. Prentice Hall Inc: New Jersey, 1997.

(available in pdfformat)

\section{GENERAL}

17. Green, Robert E. "Nondestructive evaluation of thick-composite fatigue damage," Proc. of the SPIE, Vol. 2459, 1995. pp. 30-41.

18. Johnson, E. C. and J. P. Nokes "NDE Techniques Assessment for Gr/Ep Composite Overwrapped Pressure Vessels, "Nondestructive Characterization of Materials, Vol 9. American Institute of Physics, 1999. pp. 269-274.

19. Thomas, G. H. "Overview of Nondestructive Evaluation Technologies." Lawrence Livermore National Laboratory, UCRL-JC-120505, March 1995.

\section{SURFACE MOUNTED STRAIN GAUGES}

20. Omega. Transacations in Measurement and Control, Vol 3, Force Related Mesurements. $2^{\text {nd }}$ ed. Putman Publishing Company and OMEGA Press LLC., 1998.

21. Wheatstone Bridge Circuit.

Available from: http://civil.colorado.edu/courseware/struct_labs/wheatstone.html

\section{THERMAL TESTING}

22. Baughman, Steve R. "Applications for Thermal NDT on Advanced Composites in Aerospace Structures." Proc. of the SPIE, 3361, 1998. pp. 311-319.

23. Jones, Thomas S. "Infrared Thermographic Evaluation of Marine Composite Structures." Proc. of the SPIE, Vol. 2459, 1995. pp. 42-50. 


\section{ACOUSTIC EMSSION}

24. Gorman, Michael. "Burst Pressure by Acoustic Emission in Filament-Wound Pressure Vessels." Journal of Acoustic Emission, Vol 9, No. 2, 1990. pp. 131-138.

25. Hill, Eric v.K. "Predicting Burst Pressures in Filament-Wound Composite Pressure Vessels by Using Acoustic Emission Data," Materials Evaluation, Vol. 50, Dec 1992. pp. 1439-1445.

26. Peacock, Martin. "Acoustic emission for detecting of process related damage in pressure vessels and piping." Proc. of the SPIE, Vol 2947, 1996. pp. 117-125.

27. Wevers, M. "The sound of materials: Acoustic emission for the analysis of materials behavior." Nondestructive Testing. Balkema, 1996, pp. 117-125.

\section{ULTRASONICS}

28. Frankle, Robert S. and Douglas N. Rose. "Flexible ultrasonic array system for inspecting thick composite structures." Proc. of the SPIE, Vol. 2459, 1995. pp. 51-59.

29. Kinra, V. K. and V. Dayal. "Nondestructive evaluation of composite material using ultrasound. John C. Duke, Acousto-Ultrasonics: Theory \& Application. Plenum Press: New York, 1988. pp. 143-150.

\section{RADIOGRAPHY}

30. Bueno, C., M. D. Barker, R. A. Betz, R. C. Barry and R. A. Buchanan. "Nondestructive evaluation of aircraft structures using high-resolution real-time radiography." Proc. of the SPIE, Vol. 2455, 1995. pp. 114-124.

31. Martz, H., et. al. "Nondestructive Computed Tomography for Pit Inspections." UCRL-ID126257, Lawrence Livermore National Laboratory, 1997.

32. "Predicting the Structural and Electronic Properties of Scintillators," E\&TR AugustSeptember 1994, Lawrence Livermore National Laboratory.

33. Waters, Amy M., et. al., "High Energy X-ray Radiography and Computed Tomography of Bridge Pins," Lawrence Livermore National Laboratory, UCRL-JC-132822, 1999. 


\section{FIBER OPTIC SENSORS}

34. Asundi, Anand, "Detecting damage in composites," Mechanical Engineering, June 1998. pp. 76-77.

35. Badcock, Rodney Alan and Gerard Franklyn Fernando. "An intensity-based optical fibre sensor for fatigue damage detection in advanced fibre-reinforced composites." Smart Material Structure, Vol 4, 1995. pp. 223-230.

36. Belleville et al. "Smart Skins - A Step Toward a Practical Fiber-Optic Sensor." FISO Technologies, Inc., 1997. Available from: http://www.fiso.com/page_lit.htm.

37. Claus, R. O., K. D. Bennett, A. M. Vengsarkar, and K. A. Murphy. "Embedded Optical Fiber Sensors for Material Evaluation." pp. 135-145.

38. Dakin, J.P. and M. Volanthen. "Distributed and Multiplexed Fibre Grating Sensors." $13^{\text {th }}$ international conference on Optical Fiber Sensors. April 1999. pp. 134-140.

39. Davies, H., L. A. Everall and A.M. Gallon. "Smart Fibre Sensors for Composite Design Improvement." Smart Fibres Ltd, Southampton, UK, 2000.

40. Degrieck, Joris and Wim De Waele, "Embedded optical fiber sensors for the permanent monitoring of filament wound pressure vessels." NDT.net-March 1999, Vol. 4, No. 3. Available from: http://www.ndt.net/article/v04n03/5/5.htm.

41. Elvin, Niell, and Christopher K. Y. Leung. "Feasibility of delamination detection with embedded optical fibers." Proc. of the SPIE, Vol 3041, 1997. pp. 527-634.

42. FISO Technologies Inc. "Fiber-Optic Strain Gauges." Available from: http://www.FISO/literature/apn_fos1_9901.pdf.

43. Foedinger, et al. "Embedded fiber optic sensor arrays for structural health monitoring of filament wound composite pressure vessels." Proc. of the SPIE, Vol 3670, 1999. pp. 289301.

44. Future Fibre Technologies Pty. Ltd. "Science of Fibre Optic Sensors." Available from: http://www.fft.com.au/backgrnd.html.

45. Giles, et al. "Distributed Optical Fiber Based Damage Detection in Composites." Proc. of the SPIE, Vol 3670, 1999. pp. 311-321.

46. James, Stephen W., Chun-Yang Wei, Chen-Chung Ye, Ralph P. Tatam and Philip E. Irving, "An Investigation of the Tensile Strength of Fibre Bragg Gratings." $13^{\text {th }}$ international conference on Optical Fiber Sensors. April 1999. pp. 38-41. 
47. McDonnell Douglas Aerospace West. Fiber with Multiple Overlapping Gratings. Author: Eric Udd. U.S. patent \#5627927. 6 May 1997.

48. Measures, Raymond M. "Progress Towards Fiber Optic Smart Structures at UITAS." Proc of the SPIE, Vol. 1370, 1990. pp.46-68.

49. Measures, R. M, N. D. W. Glossop, J. Lymer, M. Leblanc, J. West, S. Dubois, W. Tsaw, and R. C. Tennyson. "Structurally integrated fiber optic damage assessment system for composite materials." Applied Optics, Vol. 28, No. 13, July 1989. pp. 2626-2633.

50. "Smart Fibers Magazine Article Portfolio." Opto \& Laser Europe Issue 55, Available at: http://smartfibers.com/SmartPages/opti.html.

51. Smart Fibers Technology. Lorna Everall, E-mail dated March 9, 2000.

52. Smart Fibers Technology. Lorna Everall, E-mail dated May 26, 2000.

53. Starodubov, D. S., et al. "Ultrastrong Fiber Grating and Their Applications." Proc. of the SPIE, Vol. 3848, 1999. pp. 178-185.

54. Waite, S.R., R.P. Tatam and A. Jackson. "Use of optical fibre for damage and strain detection in composite materials." Composites, Vol 19, No. 6, November 1988. pp. 435-442.

55. Lawrence Livermore National Laboratory. Steve DeTeresa, Email dated August 9, 2000. 


\section{APPENDIX \\ More resources for nondestructive testing research}

\section{GENERAL}

Websites:

- NDTech Online

Nondestructive Testing products, services, consulting, newsletters, links Available at: http://www.ndtech.net

- NDE Links

Available at: http://www.ntiac.com/links/index.html

- NDT.net

Online journal of Nondestructive Testing

Available at: http://www.ndt.net

\section{Contacts:}

- Harry Martz, Director of Nondestructive Testing Center

Lawrence Livermore National Laboratory

E-mail: martz2@llnl.gov

- Emmanuel Papadakis, President

Quality Systems Concepts Inc.

Technical consulting in nondestructive testing, ultrasonic technology, quality systems, and management decision

Tele: (717) 355-9809

\section{SURFACE MOUNTED STRAIN GAUGES}

\section{Industries:}

- Measurements Group

Available at: http://www.measurementsgroup.com

- Omega Engineering, Inc.

Available at: http://www.omega.com 


\section{ACOUSTIC EMISSION \& ULTRASONICS}

Industries:

- Digital Wave Corporation

Develops and manufactures acoustic emission and ultrasonic testing systems Available at: http://www.digitalwavecorp.com

- Physical Acoustics Corporation

Designs and manufactures acoustic emission sensors/instruments

Available at: http://www.pacndt.com

\section{Contacts:}

- Albert E. Brown, Lawrence Livermore National Laboratory Manufacturing and Materials Engineering Division

E-mail: brown5@llnl.gov

\section{FIBER OPTIC SENSORS}

\section{Industries/Research Centers:}

- Blue Road Research

Research and development of fiber optic sensors

Available at: http://www.bluerr.com

- Boeing Company

Develops enhancements to fiber optic sensor technology

Available at: http://www.boeing.com

- FISO Technologies:

Develops and manufactures fiber optic sensors (Fabry-Perot strain gauges) and transducers

Available at: http://www.fiso.com

- Smart Fibres Ltd.

Develops and manufactures optical fiber loading monitoring system using Bragg grating sensors

Available at: http://www.smartfibres.com

Contact: Dr. Lorna Everall

E-mail: leverall@smartfibres.com

Tele: $\quad+44(0) 2380454639$ 


\section{Universities:}

- University of Toronto, Institute for Aerospace Studies Fiber Optic Sensors and Smart Materials/Structures Available at: http://arrow.utias.utoronto.ca/test/res/ep/foss-proj.htm

- University of Southampton, Optoelectronics Research Centre Available at: http://www.soton.ac.uk/index.html

\section{Websites:}

- Fiber optic sensors links

Available at:

http://www.me.udel.edu/ wangt/Research/Current/sensor/sensor_link.html 